\title{
EMBEDDED THROUGH-SECTION SHEAR STRENGTHENING TECHNIQUE USING STEEL AND CFRP BARS IN RC BEAMS OF DIFFERENT PERCENTAGE OF EXISTING STIRRUPS
}

\author{
Authors: Breveglieri M. ${ }^{1}$, Aprile A. ${ }^{2}$, Barros J.A.O. ${ }^{3}$ \\ ${ }^{1}$ Phd student, ENDIF, Dep. of Eng., University of Ferrara, 44121 Ferrara, Italy, matteo.breveglieri@ unife.it \\ ${ }^{2}$ Assistant Professor, ENDIF, Dep. of Eng., University of Ferrara, 44121 Ferrara, Italy, alessandra.aprile@unife.it \\ ${ }^{3}$ Full Professor, ISISE, Dep. of Civil Eng., Univ. of Minho, Azurém, 4810-058 Guimarães, Portugal, barros@ civil.uminho.pt
}

\begin{abstract}
The Embedded Through-Section (ETS) technique is a promising technique for the shear strengthening of existing (RC) elements. According to this technique, holes are drilled through the beam section, and bars of steel or FRP material are introduced into these holes and bonded to the concrete with adhesive materials. An experimental program was carried out with RC T-cross section beams strengthened in shear using the ETS steel bars and ETS CFRP rods. The research is focused on the evaluation of the ETS efficiency on beams with different percentage of existing internal transverse reinforcement $\left(\rho_{\mathrm{sw}}=0.0 \%, \rho_{\mathrm{sw}}=0.1 \%\right.$ and $\left.\rho_{\mathrm{sw}}=0.17 \%\right)$. The effectiveness of different ETS strengthening configurations was also investigated. The good bond between the strengthening ETS bars and the surrounding concrete allowed the yield initiation of the ETS steel bars and the attainment of high tensile strains in the ETS CFPR rods, leading to significant increase of shear capacity, whose level was strongly influenced by the inclination of the ETS bars and the percentage of internal transverse reinforcement.
\end{abstract}

Key words: Reinforced Concrete Beams, Shear strengthening, ETS technique, Embedded Through-Section Technique, ETS steel bars, ETS CFRP bars, Existing stirrups.

\section{Introduction}

To avoid brittle and unpredictable failures due to lack of shear resistance in RC elements, strengthening techniques based on the use of fiber reinforced polymer (FRP) materials have been proposed and developed in 
the last two decades [1-4]. The efficiency of these techniques relies on the bond of performance of concreteadhesive-FRP interfaces. It has been demonstrated that the Near Surface Mounted (NSM) technique assures better bond conditions for the FRP strengthening systems than the externally bonded reinforcement (EBR) technique due to the higher confinement applied by the surrounding concrete to the FRPs [5-8]. It was also realized that as deeper is introduced a NSM FRP system into the groove opened on the concrete cover, as higher is the strengthening effectiveness of this system $[9,10]$. The Embedded Through-Section (ETS) technique was recently proposed for the shear strengthening or RC beams [11]. According to this technique, steel or FRP bars are inserted into holes drilled through the cross section, and are bonded to the surrounding concrete with an epoxy adhesive. In case of ETS technique, this concrete is able to provide a high confinement to the ETS bars, which increases the bond strength. Furthermore, a larger concrete fracture surface is mobilized during the pullout process of a ETS bar crossing the shear crack, when compared to the case of a NSM FRP strengthening system. When concrete cover has not the bond strength requisites to guarantee the aimed strengthening effectiveness for the EBR or NSM techniques, ETS strategy can be a technical and economic alternative since it mobilizes the beam's concrete core that is generally the less damaged zones of a beam. Significant increase of shear capacity was pointed out by Valerio et al. [11,12] who investigated the use of the ETS technique for the shear strengthening of RC existing bridges, and performed pullout tests for assessing the strengthening effectiveness of adhesive materials, and different embedment lengths for the ETS bars. The shear stress transfer mechanism developed in an ETS bar was studied by Barros et al. [13]. In this context, direct shear tests were executed with the purpose of capturing the main features of FRP/steel ETS bars as shear strengthening systems. From these tests it was verified that steel bars were notably effective for this purpose. Chaallal et al. [14] carried out experimental tests to compare the shear strengthening effectiveness of the ETS, NSM and EBR techniques based on the use of vertical CFRP bars applied on RC beams that were reinforced with different percentage of internal steel stirrups. It was verified that the ETS technique has provided the highest strengthening efficiency, and it was able to convert shear failure into a flexural failure. An experimental program was carried out by Barros and Dalfré [15] with RC beams shear strengthened with ETS steel bars. The variables examined in this experimental program were the width of the beam's web, the percentage and inclination of the ETS bars, the spacing of steel 
stirrups and their interaction with the strengthening bars. A significant increase of load carrying capacity was obtained (up to 124\%), proving that the use of ETS steel bars can be a very effective and cost-competitive shear strengthening technique. The beams with the higher percentage of ETS bars have failed in bending, despite the very high percentage of flexural reinforcement used. The ETS technique can also be extended to punching shear strengthening of concrete slabs $[16,17]$.

Shear is a complex phenomenon due to the high number of parameters that affect shear behavior, which justifies to be not yet completely addressed. The parameters that influence the shear behavior of a strengthened RC element are already identified [18-20]. International guidelines on the use of FRPs [21-24] take into account only a restricted number of factors, ignoring the influence, for instance, of existing transverse reinforcement. The interaction between the strengthening system and the existing internal transverse reinforcement has been investigated for the EBR and NSM techniques, and some design approaches have been proposed in these respect [25-30].

The present work aims to contribute to a deeper understanding of the ETS shear strengthening mechanisms, and the susceptibility of these mechanisms to the interaction between ETS bars and existing steel stirrups. The ultimate purpose of this work is to provide useful data for the establishment of design guidelines on the shear strengthening of RC beams using the ETS technique. The experimental program was conceived for assessing the influence on the ETS shear strengthening effectiveness of the percentage, inclination and material type of the ETS systems. For this purpose, three series of RC T-cross section beams with different percentage of internal transverse reinforcement $\left(\rho_{\mathrm{sw}}=0.0 \%, \rho_{\mathrm{sw}}=0.1 \%\right.$ and $\left.\rho_{\mathrm{sw}}=0.17 \%\right)$ were tested. The experimental program is described in detail and the relevant results are presented and discussed.

\section{Experimental program}

\subsection{Test series}

Fig. 1 presents the geometry and the reinforcement arrangements of the nineteen $\mathrm{T}$ cross section beams of the experimental program. The reinforcement system was designed according to the Eurocode 2 [31], using an high 
percentage of longitudinal reinforcement $\left(\rho_{\mathrm{sl}}=2.79 \%\right)$ in order to force the occurrence of shear failure mode for all the beams of the experimental program. To localize shear failure in one of the beam's shear spans, a three point load configuration was selected, with a different length of the beam shear spans. The monitored beam span $\left(\mathrm{L}_{1}=0.9 \mathrm{~m}\right)$ is 2.5 times the effective depth of the beam's cross section $\left(\mathrm{L}_{1} / \mathrm{d}=2.5\right)$, since according to the available research [32], beyond this limit the arch effect is negligible. To avoid shear failure in the $\mathrm{L}_{2}$ beam span, steel stirrups $\$ 8 @ 90$ mm were applied in this span. Different shear reinforcement systems were applied in the $\mathrm{L}_{1}$ beam's span of the tested beams. In fact, the experimental program consisted of the following three series of beams: 0S-Series that does not have conventional steel stirrups; 2S-Series that has steel stirrups $\phi 6 @ 300$ mm, corresponding to a shear reinforcement ratio $\rho_{s w}=0.10 \%, 4 \mathrm{~S}$-Series that has steel stirrups $\phi 6 @ 180 \mathrm{~mm}$, corresponding to a shear reinforcement ratio $\rho_{s w}=0.17 \%$, where:

$$
\rho_{s w}=\frac{A_{s w}}{b_{w} s_{s w}}
$$

being $\mathrm{A}_{\mathrm{sw}}$ the cross sectional area of the two legs of a steel stirrup, $s_{s w}$ the spacing of the steel stirrups, and $b_{w}=180 \mathrm{~mm}$ the width of the beam's web.

Each series has a reference beam without any strengthening system (Fig. 1, Fig.2), and four beams with different ETS strengthening configurations (Fig. 3). The investigated parameters are the shear strengthening ratio $\left(\rho_{f w}\right)$ and the inclination $\left(90^{\circ}, 45^{\circ}\right)$ of the ETS bars, as well as the influence of the percentage of existing steel stirrups. In particular, the shear strengthening ratio of the ETS steel bars and ETS CFRP rods was defined as follows:

$$
\rho_{f w}=\frac{A_{f w}}{b_{w} s_{f w} \sin \alpha_{f}}
$$

where $A_{f w}$ is the cross sectional area of ETS bar, and $s_{f w}$ and $\alpha_{f}$ represent the spacing and inclination of this bar, respectively.

The influence of the material type of the ETS bars used for the strengthening was also investigated, by having beams strengthened with CFRP and steel bars in both $2 \mathrm{~S}$ and $4 \mathrm{~S}$ series of beams. The diameter of the ETS steel and CFRP bars was 10 and $8 \mathrm{~mm}$, respectively. A smaller diameter for the CFRP bar was chosen in order that 
the estimated force at the debonding of this bar was similar to the force at yield initiation of the steel bar. Based on previous experiences $[11,14,15]$, it was considered for the strain at debonding of this type of CFRP bars a value in the interval $0.55-0.6 \%$. Table 1 indicates the designation adopted for each beam and the strengthening configurations, namely, the number of applied ETS bars, inclination, spacing, shear strengthening ratio ( $\rho_{\mathrm{fw}}$ ), as well as the percentage of steel stirrups $\left(\rho_{\mathrm{sw}}\right)$ and total shear reinforcement $\left(\rho_{\mathrm{sw}}+\rho_{\mathrm{fw}}\right)$ calculated from Eq $(1)$ and Eq (2). Fig. 3 shows the strengthening configurations of the two tested series. As previously demonstrated by Barros and Dalfré [15], the effectiveness of the ETS bars is higher if they are placed in between existing stirrups. Following this approach, the strengthening arrangements indicated in Table 1 and Fig. 3 were adopted, leading to four different $\rho_{\mathrm{fw}}$ values. The ETS strengthening ratio varied between $0.15 \%$ (ETS vertical bars spaced at 300 $\mathrm{mm}$ ) and $0.34 \%$ (ETS bars at $45^{\circ}$ and spaced at $180 \mathrm{~mm}$ ). Two strengthening ratio values were adopted in the beams strengthened with ETS CFRP bars, $\rho_{\mathrm{sw}}=0.16$ (vertical bars spaced at $\left.180 \mathrm{~mm}\right)$, and $\rho_{\mathrm{sw}}=0.22\left(\right.$ bars at $45^{\circ}$ spaced at $180 \mathrm{~mm})$

\subsection{Material properties}

The concrete average compressive strength $\left(f_{c m}\right)$ of the beams was evaluated at 28 days and at the age of the beams' test, by carrying out direct compression tests on cylinder specimens of $150 \mathrm{~mm}$ diameter and $300 \mathrm{~mm}$ height according to EN 206-1 (2004) [33]. It was obtained an $f_{c m}$ equal to 24.7 and $29.7 \mathrm{MPa}$ at 28 days and at the day of the test (approximately 255 days), respectively, for the first batch (0S-Series and 2S-Series) and 27.6 and 32.3 MPa, at 28 days and at the day of the test (approximately 250 days) for the second batch (4S-Series and CFRP ETS strengthened beams), respectively. For the internal reinforcement of the beams, high bond steel bars of $6,10,8,12$, and $24 \mathrm{~mm}$ diameter were used. The steel class is B $450 \mathrm{C}\left(f_{y k}=450 \mathrm{MPa}\right)$ according to the Italian Construction Code. [34]. The yield stress and tensile strength were obtained by means of uniaxial tensile tests performed according to recommendations of UNI EN ISO 6892-1:2009 [35]. For the steel bars of 6, 8, 10, 12 and $24 \mathrm{~mm}$ diameter it was obtained an average yield stress of $574\left(\varepsilon_{\mathrm{sy}}=0.287 \%\right), 505\left(\varepsilon_{\mathrm{sy}}=0.253 \%\right), 549\left(\varepsilon_{\mathrm{sy}}=\right.$ $0.275 \%), 527\left(\varepsilon_{\mathrm{sy}}=0.264 \%\right)$ and $598\left(\varepsilon_{\mathrm{sy}}=0.299 \%\right) \mathrm{MPa}$, and an average tensile strength of $667,594,642,617$ and $708 \mathrm{MPa}$, respectively. The adopted ETS steel bars were of the same class of the bars used for the flexural reinforcement and steel stirrups applied in the beams. To bond the ETS steel bars to the concrete substrate the 
Sikadur $32 \mathrm{~N}$ epoxy based adhesive was used. The tensile behavior of this adhesive was characterized by carrying out direct tensile tests according to the ISO 527-2 [36], having been obtained an average tensile strength of 20.7 MPa and an elasticity modulus of 3.27 GPa. The pultruded carbon fiber sandblasted 8mm rod, MasterBrace BAR 8 CFS [37], has an elasticity modulus of $130 \mathrm{GPa}$ and an ultimate strain of $1.8 \%$.

\subsection{Strengthening technique}

To simplify the drilling process and to avoid the possibility of intersecting the longitudinal bars, the execution of the ETS strengthening process was executed with the beam's web turned upward. The ETS strengthening technique was composed of the following steps: (1) Holes of $16 \mathrm{~mm}$ diameter for the ETS steel bars, and holes of $14 \mathrm{~mm}$ for the ETS CFRP bars were drilled in the beam core. The holes length was defined by preserving 20 $\mathrm{mm}$ of intact concrete cover at the lower side of the beam, in order to avoid the adhesive flow through the bottom part of the hole. During the drilling process the concrete dust was aspired using a vacuum system. (2) The holes were cleaned by using an helicoidally steel brush capable of removing the particles from the walls of the hole, which were then eliminated by the vacuum system; the cleaning procedure was repeated until the dust was definitely removed. (3) The epoxy resin was prepared according to the recommendations of the supplier, and was slowly poured into the holes. (4) The ETS bars were cut in the desired length, cleaned with acetone, and were slowly introduced into the holes removing the resin in excess. To guarantee a proper curing of the adhesive, the beams were tested at least two weeks after the ETS application.

\subsection{Test set up and monitoring system}

Fig. 4 shows the position of the displacement transducers (LVDTs) and force transducers used for measuring the beam's deflection and applied/reaction forces, respectively. The LVDTs were supported in a bar fixed at the beams supports' sections in order to register displacements only caused by the deflection of the beam. The displacement transducer TR1 was used to control the tests at a displacement rate of $10 \mu \mathrm{m} / \mathrm{s}$ up to the failure of the beams. The beams were loaded under three-point bending configuration with a shear span of $900 \mathrm{~mm}$. The applied load (F) was measured using a force transducer of $\pm 750 \mathrm{kN}$ capacity and accuracy of $\pm 0.1 \%$. A second 
force transducer of $\pm 500 \mathrm{kN}$ capacity and $0.1 \%$ accuracy was under the support corresponding to the longer span $\left(\mathrm{L}_{2}\right)$ to complement the information for a full assessment of the shear force in each span of the beam. To obtain the strain variation in steel stirrups and ETS bars, electrical strain gauges (SGs) were bonded on selected cross sections of stirrups and ETS bars that have the highest probability of providing the largest contribution for the shear strengthening of the RC beam. Eight and five SGs for each beam of series without stirrups (0S-Series) and beam with stirrups (2S and 4S Series), respectively, were installed on ETS bars according to the configuration represented in Figs 5a and 5b. In ETS CFRP strengthened beams, six SGs were installed on a CFRP bar, and two SGs were applied on an internal steel stirrups. The monitoring SGs system in CFRP strengthened beams was slightly different of the one adopted in the steel strengthened beams, and the position of the SGs is indicated in Fig.5c.

\section{Results}

\subsection{Load carrying capacity of the tested beams.}

The load (F)-deflection $\left(\mathrm{u}_{\mathrm{L}}\right)$ diagrams are presented Fig.6 for 0S Series, 2S Series and 4S Series. All the beams showed the same behavior up to the formation of the first diagonal crack, that has formed at an approximate load of $113 \mathrm{kN}\left(\mathrm{u}_{\mathrm{L}}=0.98 \mathrm{~mm}\right), 100 \mathrm{kN}\left(\mathrm{u}_{\mathrm{L}}=0.91 \mathrm{~mm}\right)$ and $135 \mathrm{kN}\left(\mathrm{u}_{\mathrm{L}}=1.37 \mathrm{~mm}\right)$ in case of the reference beams $0 \mathrm{~S}-\mathrm{Ref}$, 2S-Ref and 4S-Ref, respectively. Fig. 7 shows the failure crack patterns obtained for all the tested beams. As already observed in beams that have been strengthened in shear with carbon fiber reinforced polymer (CFRP) laminates, installed according to the NSM technique [38], the stiffness degradation of the ETS strengthened beams is generally smaller than that of the reference beams. The ETS steel bars bridging the shear cracks surfaces offer resistance to crack opening and sliding, enhancing concrete's contribution to the shear resistance due to the aggregate interlock effect, which leads a higher load carrying capacity after shear crack initiation. The ETS strengthening technique increased significantly the maximum load carrying capacity and ultimate deflection capacities of the beams, whose performance level depends on the shear reinforcement/strengthening arrangement. All the beams exhibited a shear failure mode, since a quite high flexural reinforcement was adopted in order to avoid flexural failure mode. The beam with the highest load carrying capacity (4S-C180-45) 
has presented a mixed-mode shear-flexural failure, and its crack pattern was characterized by the opening of two large diagonal cracks, followed by the crushing of the concrete at the loaded section at failure (Fig.7). The main results of the experimental tests are presented in Table 2, where $\mathrm{F}_{\max }$ is the maximum load attained by the beams and $\mathrm{u}_{\mathrm{Lmax}}$ is the displacement in the loaded section at $\mathrm{F}_{\max }$. The strengthening efficiency of the ETS technique can be evaluated by considering the $\Delta \mathrm{F} / \mathrm{F}_{\mathrm{Ref}}$ ratio, where $\mathrm{F}_{\mathrm{Ref}}$ is the maximum load of the reference beam, and $\Delta \mathrm{F}=\mathrm{F}_{\max }-\mathrm{F}_{\mathrm{Ref}}$ is the increase of maximum load provided by each ETS arrangement. The Table 2 also includes the maximum shear force $\mathrm{V}_{\max }\left(=0.6 \mathrm{~F}_{\max }\right)$ applied in the $\mathrm{L}_{1}$ beam's span (Fig. 1) and the resisting shear force

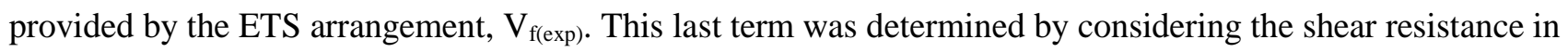
the 0S-Ref, 2S-Ref and 4S-Ref reference beams, by assuming as valid the principle that the shear resistance of a beam reinforced with steel stirrups and strengthened with ETS bars is the addition of the contributions of the concrete, steel stirrups and ETS bars. The last two columns in this table include, respectively, the tangent $\left(\mathrm{CDC}_{\text {tang }}\right)$ and the average $\left(\mathrm{CDC}_{\mathrm{avg}}\right)$ inclination of the failure shear crack $(\mathrm{CDC})$, whose evaluation process is schematically represented in Fig. 7, for $0 \mathrm{~S}-\mathrm{Ref}$ beam. For the evaluation of the $\mathrm{CDC}_{\mathrm{tang}}$, an auxiliary horizontal line at half distance from the longitudinal reinforcement to the bottom surface of the beam's flange $\left(\mathrm{d}_{1}\right.$ represented in OS-Ref beam in Fig. 7) was introduced; then the point of its interception with the CDC was determined. The $\mathrm{CDC}_{\text {tang }}$ is the inclination of the $\mathrm{CDC}$ at this point of interception. The $\left(\mathrm{CDC}_{\mathrm{avg}}\right)$ is determined by connecting the points of the interception of the CDC with the bottom surface of the beam's flange and the longitudinal reinforcement. According to the obtained results, the $\left(\mathrm{CDC}_{\text {tang }}\right)$ was usually higher than $\left(\mathrm{CDC}_{\mathrm{avg}}\right)$. The values of $\left(\mathrm{CDC}_{\text {tan }}\right)$ have ranged from $34^{\circ}$ to $73^{\circ}$. By considering all the tested beams, an average value of $\mathrm{CDC}_{\mathrm{avg}}=45^{\circ}$ was obtained. It is possible to notice that the beams with the highest percentage of shear reinforcement $\left(\rho_{\mathrm{ws}}+\rho_{\mathrm{wf}}\right)$ and the CFRP strengthened beams exhibited higher inclinations of the $\mathrm{CDC}_{\text {avg. }}$. 2S-S180-90 and 2S-C180-90 beams presented high inclinations of critical diagonal crack, probably due to the less evenly distributed of the shear reinforcements. Fig. 7 clearly shows that the number of diagonal cracks increased with the percentage of transverse steel reinforcement.

The load vs. deflection relationship of the beams of OS-Series is indicated in Fig. 6a. This series is characterized by the absence of stirrups in the strengthened shear $\operatorname{span}\left(\rho_{\mathrm{ws}}=0.0 \%\right)$. Due to the detrimental interaction effect 
between existing steel stirrups and strengthened systems in the context of the shear strengthening effectiveness [27], the beams of this series presented the highest strengthening efficiency amongst the tested series, with an increase of load carrying capacity that ranged from $40 \%$ to $136 \%$. For the ETS vertical bars, the beams with the lowest percentage of ETS bars, $\rho_{\mathrm{fw}}=0.15 \%$ (0S-S300-90), and with the highest $\rho_{\mathrm{fw}}=0.24 \%$ (0S-S180-90) presented an increase of load carrying capacity of $39.5 \%\left(\mathrm{~F}_{\max }=217.8 \mathrm{kN} ; \mathrm{u}_{\mathrm{Lmax}}=4.37 \mathrm{~mm}\right)$ and $64.6 \%\left(\mathrm{~F}_{\max }=\right.$ $\left.256.8 \mathrm{kN} ; \mathrm{u}_{\mathrm{Lmax}} 4.31 \mathrm{~mm}\right)$, respectively. The highest increase of load carrying capacity was obtained in the beams with ETS bars inclined at $45^{\circ}$. In fact the beam with the lowest $\rho_{\mathrm{fw}}=0.24 \%$ (OS-S300-45) and with the highest $\rho_{\mathrm{fw}}=0.34 \%$ (0S-S180-45) presented an increase of load carrying capacity of $123.4 \%\left(\mathrm{~F}_{\max }=348.6 \mathrm{kN}\right)$ and of $136.3 \%\left(\mathrm{~F}_{\max }=368.8 \mathrm{kN} ; \mathrm{u}_{\mathrm{Lmax}}=6.56 \mathrm{~mm}\right)$, respectively. This indicates that the inclination of the ETS bars seems to have a higher contribution for the strengthening effectiveness that the spacing of these bars, as long as this distance assures that a CDC is crossed by an effective ETS bar (with an enough bond length to avoid premature debonding), which is in agreement with the tendency observed in the NSM technique [27]. The load vs. deflection relationship of the beams of 2S-Series is depicted in Fig. 6b. This series is shear reinforced with 2-arms $\phi 6 \mathrm{~mm}$ steel stirrups $@ 300 \mathrm{~mm}\left(\rho_{\mathrm{ws}}=0.10 \%\right)$. For the ETS vertical bars, the beams with the lowest percentage of ETS bars, $\rho_{\mathrm{fw}}=0.15 \%$ (2S-S300-90), and with the highest percentage, $\rho_{\mathrm{fw}}=0.24 \%(2 \mathrm{~S}$ S180-90), have presented an increase of load carrying capacity of $30.4 \%\left(F_{\max }=315.7 \mathrm{kN} ; \mathrm{u}_{\mathrm{Lmax}}=5.32 \mathrm{~mm}\right)$ and $68.1 \%\left(\mathrm{~F}_{\max }=406.8 \mathrm{kN} ; \mathrm{u}_{\mathrm{Lmax}} 8.27 \mathrm{~mm}\right)$, respectively. Like already occurred in the beams of the 0S-Series, in the $2 \mathrm{~S}-$ Series the highest strengthening effectiveness has occurred in the beams with ETS bars inclined at $45^{\circ}$. In fact, the beam with the lowest percentage, $\rho_{\mathrm{fw}}=0.24 \%(0 \mathrm{~S}-\mathrm{S} 300-45)$, and with the highest percentage, $\rho_{\mathrm{fw}}=$ $0.34 \%(2 \mathrm{~S}-\mathrm{S} 180-45)$, presented an increase of the load beam carrying capacity of $68.2 \%\left(\mathrm{~F}_{\max }=407.1 \mathrm{kN}\right.$; $\mathrm{u}_{\mathrm{Lmax}}$ $7.03 \mathrm{~mm})$ and $108.5 \%\left(\mathrm{~F}_{\max }=504.7 \mathrm{kN} ; \mathrm{u}_{\mathrm{Lmax}}=8.37 \mathrm{~mm}\right)$, respectively.

The load vs. deflection relationship of the beams of the 4S-Series is illustrated in Fig. 6c. This series is shear reinforced with 2-arms $\phi 6 \mathrm{~mm}$ existing steel stirrups @180 mm $\left(\rho_{\mathrm{ws}}=0.17 \%\right)$. For the ETS vertical bars, the beams with the lowest percentage of ETS bars, $\rho_{\mathrm{fw}}=0.15 \%$ (4S-S300-90), and with the highest percentage, $\rho_{\mathrm{fw}}=$ $0.24 \%$ (4S-S180-90), presented an increase of load carrying capacity of $4.8 \%\left(\mathrm{~F}_{\max }=370.9 \mathrm{kN} ; \mathrm{u}_{\mathrm{Lmax}}=7.43 \mathrm{~mm}\right)$ and $16.8 \%\left(\mathrm{~F}_{\max }=413.2 \mathrm{kN} ; \mathrm{u}_{\mathrm{Lmax}}=6.32 \mathrm{~mm}\right)$, respectively. The decrease of the shear strengthening 
effectiveness with the increase of existing shear reinforcement is quite evident, and will be discussed in more detail in Section 5. Furthermore, for configuration 4S-S300-90 a $\mathrm{V}_{\mathrm{f}(\exp )}$ of $10.3 \mathrm{kN}$ indicates that the contribution provided by the only ETS bar crossed by the shear crack was low, due to its small resisting bond length (Fig7). The results of this beam showed the importance of the adopted strengthening geometry, revealing that strengthen elements should be placed in between stirrups $[15,28]$. For the beams with ETS bar inclined at $45^{\circ}$ a higher increase of load carrying capacity was obtained. In fact, the beams with the lowest percentage of ETS bars, $\rho_{\mathrm{fw}}=$ $0.24 \%$ (4S-S300-45), and with the highest percentage, $\rho_{\mathrm{fw}}=0.34 \%$ (4S-S180-45), presented an increase of load carrying capacity of $56.1 \%\left(\mathrm{~F}_{\max }=552.4 \mathrm{kN} ; \mathrm{u}_{\mathrm{Lmax}}=12.03 \mathrm{~mm}\right)$ and $60.1 \%\left(\mathrm{~F}_{\max }=566.4 \mathrm{kN} ; \mathrm{u}_{\mathrm{Lmax}}=11.01 \mathrm{~mm}\right)$, respectively. These results indicate that by increasing the percentage of existing steel stirrups, the influence of the inclination of the ETS bars in terms of shear strengthening effectiveness becomes larger, while the influence of the spacing of ETS bars becomes smaller.

The shear strengthening effectiveness of CFRP bars was also investigated, by strengthening two beams of both 2S-Series and 4S-Series. The load vs. deflection relationship of the beams strengthened with ETS CFRP bars is indicated in Fig. $6 b$ for 2 S-Series and in Fig. $6 c$ for 4 S-Series. For the CFRP vertical bars, $\rho_{\mathrm{fw}}=0.16 \%$ (CFRP180-90), the beams presented an increase of load carrying capacity of $53.1 \%\left(\mathrm{~F}_{\max }=370.49 \mathrm{kN}\right.$; $\mathrm{u}_{\mathrm{Lmax}}=$ $6.89 \mathrm{~mm})$ and $6.5 \%\left(\mathrm{~F}_{\max }=376.88 \mathrm{kN} ; \mathrm{u}_{\mathrm{Lmax}}=6.2 \mathrm{~mm}\right)$ for $2 \mathrm{~S}$ - and 4S-Series, respectively. For the ETS CFRP bars inclined at $45^{\circ}, \rho_{\mathrm{fw}}=0.22 \%$ (CFRP180-45), the beams presented an increase of load carrying capacity of $120.9 \%\left(\mathrm{~F}_{\max }=534.69 \mathrm{kN} ; \mathrm{u}_{\mathrm{Lmax}}=9.53 \mathrm{~mm}\right)$ and $74.4 \%\left(\mathrm{~F}_{\max }=616.86 \mathrm{kN} ; \mathrm{u}_{\mathrm{Lmax}}=12.03 \mathrm{~mm}\right)$ for $2 \mathrm{~S}-$ and $4 \mathrm{~S}-$ Series, respectively. A lower strengthening performance was observed for the vertical CFRP bars when compared to the vertical steel bars due the strengthening configuration. In fact, the available bond length of the CFRP bar crossed by the CDC was not sufficient to develop high tensile strains in this type of bars. However, when the strengthening configuration provided an adequate bond length, as was the case of inclined bars, a higher load carrying capacity was obtained by using CFRP bars instead of steel bars. The results obtained in the beams strengthened with ETS CFRP bars demonstrate that the decrease of the shear strengthening effectiveness with the increase of the reinforcement ratio of existing steel stirrups occurs regardless of the type of material adopted for the ETS bars. 


\subsection{Strains in the ETS bars/rod and steel stirrups.}

The relationships between the force applied in the beams and the strains registered in the most representative SGs installed in the monitored ETS bars and stirrups are shown in Fig. 8, while in Table 3 are included the relevant results, where $\varepsilon_{\mathrm{Fmax}}$ is the strain measured at $\mathrm{F}_{\max }$, while $\varepsilon_{\max }$ is the maximum strain recorded in the ETS bars and stirrups. For the $\varepsilon_{\max }$ it is also provided the value of the $\mathrm{u}_{\mathrm{L}} / \mathrm{u}_{\mathrm{Lmax}}$ parameter, in order to indicate if $\varepsilon_{\mathrm{Fmax}}$ has occurred in pre- $\left(\mathrm{u}_{\mathrm{L}} / \mathrm{u}_{\mathrm{Lmax}}<1\right)$ or post-peak $\left(\mathrm{u}_{\mathrm{L}} / \mathrm{u}_{\mathrm{Lmax}}>1\right)$ phase of the beam's force-deflection response. The recorded strain values are quite dependent on the distance between the SG and the shear failure crack. This effect is quite visible in beams strengthened with vertical ETS bars, in which relatively high strain values have been measured in zones of the ETS bars crossed by a shear crack (Figs 8a and 8d). For instance, large strains at $\mathrm{F}_{\max }$ have been recorded in SG No.4 of the 0S-S180-90 beam (0.59\% at $\mathrm{F}_{\max }$ ) (Fig8a), SG No.8 of the 2S-C180-90 beam $\left(0.67 \%\right.$ at $\left.\mathrm{F}_{\max }\right)(\mathrm{Fig} 8 \mathrm{~d})$, SG No.7 for the $4 \mathrm{~S}-\mathrm{S} 180-90\left(\varepsilon=88 \%\right.$ at $\left.\mathrm{F}_{\max }\right)$. The designation attributed to the strain gauges in Table 3 for the ETS bars and steel stirrups (second and third column) is represented in Figs. 5 and 8 in order to highlight the relative position between the SGs and the shear cracks, and to help a better interpretation of the obtained results. Furthermore, the strain values are quite dependent on the available bond length of the elements they are installed. If the available bond length is relatively small, the steel bars cannot attain the yield strain due to slip occurrence, as was the case of SG No.4 of the 4S-S180-90 beam ( $\varepsilon=0.04 \%$ at $\left.\mathrm{F}_{\max }\right)$ and SG No.1 of the $0 \mathrm{~S}-\mathrm{S} 180-90\left(\varepsilon=0.16 \%\right.$ at $\left.\mathrm{F}_{\max }\right)$. For the same reason, CFRP bars can record low strain even if the bars are crossed by the critical shear crack, as was the case of SG No.4 of the 2S-C180-90 beam $\left(\varepsilon=0.27 \%\right.$ at $\left.\mathrm{F}_{\max }\right)$.

Higher strains have been recorded in both inclined ETS steel and CFRP bars, thanks to the adopted strengthening configuration that provided longer force transfer length and, consequently, higher increase of load carrying capacity. It was verified that steel ETS bars have reached the yield strain in the sections where they were crossed by the critical shear crack and also by a secondary diagonal crack, as occurred in the beams 0S-S300-45, 0SS180-45, 2S-S300-45, 2S-S180-45, 4S-S300-45, and 4S-S180-45 (Fig. 8). In some of the tested beams, the excellent bond conditions provided by the concrete core allowed the steel yield strain to be exceeded in more 
than one section of the same ETS bar crossing shear cracks, such was the case, for instance, 4S-S300-45 beam (Fig.8c) with $\varepsilon=0.91 \%$ in $S G$ No.6 at $0.75 \mathrm{u}_{\mathrm{L}} / \mathrm{u}_{\mathrm{Lmax}}$ and $\varepsilon=0.90 \%$ in $\mathrm{SG}$ No.8 at $0.82 \mathrm{u}_{\mathrm{L}} / \mathrm{u}_{\mathrm{Lmax}}$ ). By using inclined bars, strain values higher than $0.8 \%$ have been usually recorded in at least one of the ETS steel bars. In all the monitored elements of the strengthened beams with inclined CFRP bars, as is the case of beams 2S-C180-45 and 4S-C180-45, higher strains were recorded due to the formation of diffuse crack patterns (Figs. 8e and 8f). For instance, in the ETS4 and ETS3 monitored sections of beams 2S-C180-45 and 4S-C180-45, a relatively high average strain of $\varepsilon=0.9 \%$ was obtained. The higher number of cracks is a consequence of the higher percentage of the ETS strengthening ratio and the larger effective bond length (in case of inclined ETS bars) that can mobilizes simultaneously bond and concrete resisting fracture mechanisms [39]. The maximum strain of $\varepsilon=1 \%$ at $0.83 \mathrm{u}_{\mathrm{L}} / \mathrm{u}_{\mathrm{Lmax}}$ was measured in the SG No.7 of beam $2 \mathrm{~S}-\mathrm{C} 180-45$. Considerable strains were also attained in case of a reduced bond length $\left(\varepsilon=0.61 \%\right.$ at $0.63 \mathrm{u}_{\mathrm{L}} / \mathrm{u}_{\mathrm{Lmax}}$ in $\mathrm{SG}$ No.4 of beam $\left.2 \mathrm{~S}-\mathrm{C} 180-45\right)$. Higher strains were generally recorded in CFRP bars than in steel bars, due to the lower elasticity modulus of the CFRP.

Steel stirrups showed a trend in terms of strain variation similar to the ETS bars, attaining relatively high strains in the sections crossed by a diagonal crack, as was the case of SG No.3 in beam 4S-S300-45 $(\varepsilon=0.89 \%$ at 0.68 $\left.\mathrm{u}_{\mathrm{L}} / \mathrm{u}_{\mathrm{Lmax}}\right)$, or SG No.3 for beam $4 \mathrm{~S}-\mathrm{C} 180-45\left(\varepsilon=0.79 \%\right.$ at $\left.0.78 \mathrm{u}_{\mathrm{L}} / \mathrm{u}_{\mathrm{Lmax}}\right)$. Moreover, the excellent anchorage conditions provided by the closed configuration of the stirrups, as well as its smaller diameter (when compared to the ETS steel bars diameter), have assured the attainment of the yield strain in several sections monitored with SG. In some of the beams, the steel stirrups have even attained its rupture (2S-S300-45, 4S-S180-90, 2SCFRP180-45, 4S-C180-45).

\subsection{Failure modes}

The ETS shear strengthening systems have failed by the debond at the bar/adhesive interface. Due to the higher confinement provided to the ETS bars by the web-flange surrounding concrete under compression, debonding which was the governing failure mode occurred in the bond length of ETS bars localized in the bottom part of the beam's cross section (apart 0S-S300-90, see Fig. 7). This type of failure has been observed either in steel (Fig. 9a) as well as in CFRP bars (Fig. 9b). In case of ETS steel bars, it was possible to observe that the ribs of 
these bars have scratched the surrounding epoxy adhesive, Fig. 9c. Despite this observed behavior, the bond performance was capable to mobilize the yield stress of the steel bars, and assured relatively high tensile strains in the CFRP bars, as reported in the previous section. This type of failure mode might justify the relatively low maximum strains recorded in the vertical ETS bars, and consequently the lower shear strengthening effectiveness when compared to the same strengthening configuration but using steel bars (Table 2). In fact, since the average direction of the shear failure cracks is about $45^{\circ}$ with the beam's axis (Table 2), during the opening and sliding process of this type of cracks, the vertical and inclined ETS bars that cross these cracks are submitted to axial and transversal force components. As already observed in a previous study [40], due to this latter component, the axial force transferred from the bar to the surrounding material increases, leading the ETS bars to scratch the surrounding epoxy adhesive. This scratching effect was also observed in the face of the CFRP bars, due to the relatively low shear resistance of the external layer of these bars, when compared to the ribs of the steel bars. The combined action of tensile and transversal forces on the bar has led, in most of cases, to the peeling-off of the external layer of the CFRP bars (Fig. 9d). The post-test inspection of the failure modes in 2SC180-45 has revealed that the bars have ruptured, probably not because the ultimate strain was attained, but a consequence of the combined tensile-shear forces applied in the bar at crack section. The type of failure characterized by the loss of bond between the steel end epoxy adhesive was also found in the bond test conducted by [11], and [41]. The types of failures reported by [42], namely, concrete fracture, and mixed concrete-fracture-debonding were not observed in the present experimental program. The concrete fracture was not observed due to the relatively high confinement of the core concrete surrounding the ETS bars when using the ETS technique. It is also possible to observe that the group effect, i.e. the tendency for the detachment of the concrete cover with the increase of the shear strengthening percentage, observed when using the NSM technique $[38,43,44]$, did not occur in the ETS technique. Due to the scratching of the epoxy adhesive, the maximum strain recorded in the ETS bars never attained the steel ultimate strain, and therefore the rupture of the steel ETS bars have never occurred. However, in case of the steel stirrups, due to the excellent anchorage conditions provided by its closed shape, the steel rupture was observed (see. $§ 3.2$ ). 


\section{Influence of the percentage and inclination of the ETS strengthening.}

Fig.10 represents the relationship between the strengthening effectiveness ratio, $\Delta \mathrm{F} / \mathrm{F}_{\mathrm{Rmax}}$, provided by the ETS strengthening arrangement, and the total percentage of transverse reinforcement ( $\left.\rho_{\mathrm{sw}+} \rho_{\mathrm{fw}}\right)$ (see also Tables 1 and 2). The $\rho_{\mathrm{sw}+} \rho_{\mathrm{fw}}$ percentage is in the range of $0.15 \%$ to $0.52 \%$, while the $\rho_{\mathrm{fw}}$ is in the interval of $0.15 \%$ to $0.34 \%$. Fig. 10 clearly shows that the shear strengthening effectiveness decreases with the increase of $\rho_{\mathrm{sw}+} \rho_{\mathrm{fw}}$. It is also visible that most effective configurations are obtained by adopting inclined ETS bars, and a marginal shear strengthening effectiveness is obtained when vertical ETS bars are applied in RC beams with a reinforcement ratio of steel stirrups higher than of about $0.17 \%$. The dashed lines identify the tendency lines of beams with the same strengthening solution and different reinforcement ratio, pointing out the importance of the internal shear ratio on the evaluation of the strengthening effectiveness (see $\S 5$ ). The higher shear effectiveness showed by the ETS inclined bars can be justified by the orientation of the diagonal cracks that tends to be almost orthogonal to the ETS bars. Furthermore, for vertical ETS bars, the total resisting bond length of the ETS system is lower than the one for the inclined bars. As demonstrated in [39,42], in the case of shear strengthening elements of nonclosed geometric configuration, such is the case of EBR and NSM reinforcements, the effective bond length has a decisive and governing importance on the shear strengthening effectiveness, since a bond length less than the critical one limits the strengthening effectiveness of the system. To have a comprehensive understanding on the influence of the investigated parameters, the information available in previous works $[11,14,15]$ have been considered. From this latter tests only the data regarding beams that failed in shear was considered, which is presented in Table 4 and Fig 11. The $\rho_{\mathrm{sw}}$ of the analyzed beams is in the range of 0.0 to $0.17 \%$ and $\rho_{\mathrm{fw}}$ in the interval of 0.04 to $0.64 \%$. Fig. 11a shows the influence of $\rho_{\mathrm{sw}}$ and $\rho_{\mathrm{fw}}$ on the shear strengthening effectiveness of $\mathrm{RC}$ beams strengthened with vertical and inclined ETS bars. It is visible the higher strengthening effectiveness of inclined ETS bars, and a tendency for an increase of this effectiveness with $\rho_{\mathrm{fw}}$, while the opposite happens with the increase of $\rho_{\mathrm{sw}}$. By projecting the results presented in Fig.11a on a $\Delta \mathrm{F} / \mathrm{F}_{\mathrm{Ref}}-\rho_{\mathrm{fw}}$ plane, and attributing to the marker a size diameter proportional to the $\rho_{\mathrm{sw}}$ of the beam it represents, the previous conclusions can be also extracted. A relatively high shear strengthening effectiveness with vertical CFRP bars was obtained by [14], but using an abnormal high shear strengthening ratio $\left(\rho_{\mathrm{fw}}=0.64 \%\right)$. Valerio et al. [11] have also obtained similar high 
shear strengthening effectiveness with smaller strengthening ratio ( $\rho_{\mathrm{fw}}=0.24 \%$ to $0.34 \%$ ), but using higher concrete strength class $\left(f_{c m, c u b e}=55\right.$ to $60 \mathrm{MPa}$ - cube strength -, instead of $f_{c m}=25 \mathrm{MPa}$ [14]), which reveals the favorable effect of concrete strength on the shear strengthening performance. However, the results also indicate that when the shear strengthening ratio is relatively small, the influence of the concrete strength on the shear strengthening effectiveness is marginal due to the inexistence of interaction between ETS bars and smaller stress field applied by ETS bars to the surrounding concrete. The trend lines of the results corresponding to the inclined and vertical ETS bars (dotted and dashed line, respectively) evidence the higher effectiveness of the former bars. The inclination of the trend line is higher for vertical ETS bars, which might be justified by a high number of beams tested without shear reinforcement for this strengthening arrangement. From the results in Figures 10 and 11, the inclined ETS CFRP bars provided higher effectiveness than inclined steel bars of similar $\rho_{\mathrm{fw}}$ and $\rho_{\mathrm{sw}}$, but a comprehensive cost competitiveness evaluation of these strengthening solutions should be made for a sustainable decision of the most appropriate one.

\section{Influence of the existing shear reinforcement on the ETS strengthening effectiveness}

As already demonstrated in beams strengthened with the ETS [14,15], EBR and NSM techniques [44-47], the effectiveness of the ETS strengthening system decrease with the increase of the $\rho_{\text {sw. }}$. Fig. 11 show this clear tendency for the ETS strengthened beams. This detrimental effect was more pronounced in case of vertical ETS bars; for instance in the case of the presented work, in ETS steel bars, spaced at $180 \mathrm{~mm}$, the $\Delta \mathrm{F} / \mathrm{F}_{\mathrm{Rmax}}$ can decrease up to $74 \%$ (by comparing the results of 0S-Series and 4S-Series). The results presented in Fig. 11 clearly show that the shear strengthening effectiveness is influenced by the shear reinforcement ratio of existing steel stirrups. The detrimental effect induced by the presence of stirrups was recently discussed and a parameter was proposed to simulate this effect $[25,30]$. In the present work it was verified that the stirrups have yielded, even in the beams with the highest $\rho_{\mathrm{sw}}$ and $\rho_{\mathrm{fw}}$. This indicates that ETS technique using steel bars can mobilize integrally the strength capacity of both shear reinforcements, and consequently, the above parameter can be neglected in this technique. In shallow RC beams shear strengthened with ETS steel bars, the resisting bond length of those bars crossed by the critical shear crack may be not enough to mobilize its yield strain. In this case 
the applicability of a reduction parameter can be justified. However, no sufficient experimental data is actually available to propose a recommendation for this parameter. Fig. 12 compares the $\Delta F / F_{R \max }$ obtained when using ETS, NSM and EBR techniques, by considering the results obtained in previous experimental programs by Dias and Barros [48], where similar RC beams were tested $\left(\rho_{\mathrm{sw}}=0.1\right.$ and $\left.\rho_{\mathrm{sw}}=0.17 \%\right)$. The highest strengthening efficiency of the ETS technique is clearly visible, mainly when using inclined ETS bars.

\section{Conclusions}

An experimental program on reinforced concrete (RC) $\mathrm{T}$ cross section beams shear strengthened with a recent technique denominated Embedded Through-Section (ETS) was described, and the relevant results are presented and discussed. The influence of the percentage of existing steel stirrups $\left(\rho_{\mathrm{sw}}\right)$ on the ETS shear strengthening effectiveness when using ETS steel or carbon fiber reinforced polymer (CFRP) bars was investigated. The inclination of these bars $\left(90^{\circ}\right.$ and $\left.45^{\circ}\right)$ on this effectiveness was also analyzed. For this purpose three series of beams with different $\rho_{\mathrm{sw}}(0.0,0.10$, and $0.17 \%)$ were tested.

From the obtained results it can be concluded that in general, a significant increase of load carrying capacity was obtained by using the proposed technique, regardless the material type of ETS bars. Vertical ETS bars provided an increase of load carrying capacity in the interval of 5\% to $68 \%$. The inclined ETS bars have assured a higher strengthening effectiveness, since an increase of load carrying capacity from $53 \%$ to $136 \%$ was obtained. The inclined ETS bars were also more effective in assuring larger deflection capacity at the failure of the beams. The higher effectiveness of inclined ETS bars is attributable to the larger available resisting bond length, and their better orientation regarding the inclination of the shear failure crack (almost mutually orthogonal).

When comparing the results from the series of beams with different $\rho_{\mathrm{sw}}$ it was verified that the strengthening effectiveness has decreased with the increase of $\rho_{\mathrm{sw}}$, and this tendency was more prone in the series with vertical ETS bars. Information in this respect was collected from available bibliography, which has confirmed the aforementioned tendency. 
By comparing the shear strengthening effectiveness obtained with the ETS technique proposed in the present work and the one assured by using the externally bonded reinforcement (EBR) and the near surface mounted (NSM) techniques it was verified that the former one is more effective.

In fact, due to the good bond conditions of ETS bars assured by the concrete core of the beams, which also introduced some favorable confinement to these bars, those made of steel have yielded, and the CFRP bars have attained a relatively high maximum tensile strain, mainly the inclined ones. For similar shear strengthening ratio, the CFRP bars provided higher shear strengthening effectiveness than steel bars, due to the larger ultimate force capable to be mobilized in incliend bars. It was also verified that the steel stirrups have exceeded its yield strain, even in the beams with the highest percentage of steel stirrups.

Taking into account the high level of shear strengthening effectiveness obtained in this experimental program, it can be concluded that ETS can assure ductile flexural failure mode in RC beams susceptible to brittle shear rupture. Moreover the ETS technique based on the use of steel bars is a cost competitive and sustainable solution for the shear strengthening of RC elements, and much less susceptible to the detrimental effect of high temperature than when using FRP systems. Corrosion of these bars can be avoided by providing a cement based cover at the bars' extremities.

\section{Acknowledgements}

The authors wish to acknowledge Elletipi S.r.l. (Ferrara, Italy) for supporting the experimental program, Interbau S.r.l. (Milano, Italy) for applying the ETS strengthening system, BASF company Italy for providing the CFRP rods and the ENDIF Geomatic Group (University of Ferrara, Italy) for monitoring the experimental program, as well as the support provided by FCT (PTDC/ECM/114511/2009). The authors wish also acknowledge the Engineering Department of the University of Ferrara for its financial support.

\section{References}


[1] Bakis CE, Bank LC, Brown VL, Cosenza E, Davalos JF, Lesko JJ, et al. Fiber-Reinforced Polymer Composites for Construction-State-of-the-Art Review. J Compos Constr 2002;6(2):73-87.

http://dx.doi.org/10.1061/(ASCE)1090-0268(2002)6:2(73)

[2] Teng JG, Chen JF, Smith ST, Lam L. Behaviour and strength of FRP-strengthened RC structures: a stateof-the-art review. Proc ICE - Struct Build 2003;156(1):51-62.

http://dx.doi.org/10.1680/stbu.2003.156.1.51

[3] De Lorenzis L, Teng JG. Near-surface mounted FRP reinforcement: An emerging technique for strengthening structures. Compos Part B Eng 2007;38(2):119-43.

http://dx.doi.org/10.1016/j.compositesb.2006.08.003

[4] Choudhury R, Suntharavadivel TG, Keleher P, Patil A. Shear strengthening of RC beam with external FRP bonding: A state-of-the-art review. In: From Mater. to Struct. Adv. through Innov., Eds: Samali B, Attard MM, Song C, CRC Press; 2013, p. 263-7.

[5] Sena-Cruz JM, Barros JAO. Bond Between Near-Surface Mounted Carbon-Fiber-Reinforced Polymer Laminate Strips and Concrete. J Compos Constr 2004;8(6):516-27.

http://dx.doi.org/10.1061/(ASCE)1090-0268(2004)8:6(519)

[6] Barros JAO, Dias SJE, Lima JLT. Efficacy of CFRP-based techniques for the flexural and shear strengthening of concrete beams. Cem Concr Compos 2007;29(3):203-17.

http://dx.doi.org/10.1016/j.cemconcomp.2006.09.001

[7] Bilotta A, Ceroni F, Di Ludovico M, Nigro E, Pecce M, Manfredi G. Bond Efficiency of EBR and NSM FRP Systems for Strengthening Concrete Members. J Compos Constr 2011;15(5):757-72.

http://dx.doi.org/10.1061/(ASCE)CC.1943-5614.0000204

[8] Seo S-Y, Feo L, Hui D. Bond strength of near surface-mounted FRP plate for retrofit of concrete structures. Compos Struct 2013;95:719-27. http://dx.doi.org/10.1016/j.compstruct.2012.08.038

[9] Oehlers DJ, Haskett M, Wu C, Seracino R. Embedding NSM FRP plates for Improved IC debonding resistance. J Compos Constr 2008;12(6):635-42. http://dx.doi.org/10.1061/(ASCE)1090$\underline{0268(2008) 12: 6(635))}$

[10] Barros JAO, Dias SJE. Assessment of the effectiveness of the NSM shear strengthening technique for deep T cross section RC beams.In: Proc. International Symposium on fiber reinforced polymers for reinforced concrete structures FRPRCS11, Guimarães, Portugal. 26-28 June 2013. p. 10.

[11] Valerio P, Ibell TJ, Darby AP. Deep embedment of FRP for concrete shear strengthening. Proc ICE Struct Build 2009;162(5):311-21. http://dx.doi.org /10.1680/stbu.2009.162.5.311

[12] Valerio P, Ibell T, Darby A. Shear Assessment and Strengthening of Contiguous-Beam Concrete Bridges Using FRP Bars. In: Proc. of the 7th international symposium on fiber reinforced polymer reinforcement for concrete structures (FRPRCS-7), Kansas City, Missouri; 6-9 Nov. 2005:825-48.

[13] Barros JAO, Dalfré GM, Trombini E, Aprile A. Exploring the possibilities of a new technique for the shear strengthening of RC elements. In: Proc. Int. Conf. Challenges Civil Construction (CCC2008), Univ. Porto, Porto, Portugal; 16-18 Apr. 2008. 
[14] Chaallal O, Mofidi A, Benmokrane B, Neale K. Embedded Through-Section FRP Rod Method for Shear Strengthening of RC Beams: Performance and Comparison with Existing Techniques. J Compos Constr 2011;15(3):732-42. http://dx.doi.org/10.1061/(ASCE)CC.1943-5614.0000174

[15] Barros JAO, Dalfré GM. Assessment of the Effectiveness of the Embedded Through-Section Technique for the Shear Strengthening of Reinforced Concrete Beams. Strain 2012;49(1):75-93.

http://dx.doi.org/10.1111/str.12016

[16] Sissakis K, Sheikh SA. Strengthening Concrete Slabs for Punching Shear with Carbon Fiber-Reinforced Polymer Laminates. ACI Struct J 2007;104(1):49-59. http://dx.doi.org/10.14359/18432

[17] Fernàndez Ruiz M, Muttoni A, Kunz J. Strengthening of Flat Slabs Against Punching Shear Using PostInstalled Shear Reinforcement. ACI Struct J 2010;107(4):434-42. http://dx.doi.org/10.14359/18432

[18] Lima JLT, Barros JAO. Reliability analysis of shear strengthening externally bonded FRP models. Proc ICE - Struct Build 2011;164(1):43-56. http://dx.doi.org/10.1680/stbu.9.00042

[19] Bousselham A, Chaallal O. Mechanisms of Shear Resistance of Concrete Beams Strengthened in Shear with Externally Bonded FRP. J Compos Constr 2008; http://dx.doi.org/12:499-512. 10.1061/(ASCE)1090-0268(2008)12:5(499)

[20] Belarbi A, Kuchma DA, Okeil AM, Bae S-W. Design Equations for Shear Capacity of Concrete Girders Strengthened in Shear with Externally Bonded FRP Sheets. In: Proc: Asia-Pacific Conference on FRP in Structures (APFIS), Hokkaido University Japan 2-4 February 2012, p. 8.

[21] Fib - Bulletin 14. Externally bonded FRP reinforcement for RC structures. Technical report by Task Group 9.3 FRP (Fiber Reinforced Polymer) reinforcement for concrete structures, Féderation Internationale du Béton - fib; July 2001. 130p.

[22] Standards Australia. CIDAR-Design guideline for RC structures retrofitted with FRP and metal plates: beams and slabs Draft 32006.

[23] American Concrete Institute. Guide for the design and con- struction of externally bonded FRP systems for strengthening concrete structures. ACI440.2R. Farmington Hills, MI: American Concrete Institute, Detroit; 2008.

[24] National Research Council 2004. Guide for design and construction of externally bonded FRP systems for strenghtening existing structures CNR-DT200 2012.

[25] Chen GM, Teng JG, Chen JF. Shear Strength Model for FRP-Strengthened RC Beams with Adverse FRP-Steel Interaction. J Compos Constr 2013;17(1):50-66. http://dx.doi.org/10.1061/(ASCE)CC.1943$\underline{5614.0000313}$

[26] Chen GM, Teng JG, Chen JF, Rosenboom OA. Interaction between Steel Stirrups and ShearStrengthening FRP Strips in RC Beams. J Compos Constr 2010;14(5):498-509. http://dx.doi.org/10.1061/(ASCE)CC.1943-5614.0000120

[27] Dias SJE, Barros JAO. Shear strengthening of RC beams with NSM CFRP laminates: Experimental research and analytical formulation. Compos Struct 2013;99:477-90.

http://dx.doi.org/10.1016/j.compstruct.2012.09.026 
[28] Chaallal O, Mofidi A. Shear Strengthening of RC Beams with Externally Bonded FRP Composites: Effect of Strip-Width-to-Strip-Spacing Ratio. J Compos Constr 2011;15(5): 732-42.

http://dx.doi.org/10.1061/(ASCE)CC.1943-5614.0000219

[29] Li A, Delmas Y. CRFP contribution to shear capacity of strengthened RC beams. Eng Struct 2001;23(10):1212-20. http://dx.doi.org/10.1016/S0141-0296(01)00035-9

[30] Pellegrino M, Modena C. Fiber-Reinforced Polymer Shear Strengthening of Reinforced Concrete Beams: Experimental Study and Analytical Modeling. ACI Struct J 2006;103(5):720-8. http://dx.doi.org/10.14359/16924

[31] European Committee for Standardization. Eurocode 2: Design of concrete structures - Part 1-1: General rules and rules for buildings Eurocode 2004.

[32] Collins MP, Mitchell D. Prestressed concrete structures. Englewood Cliffs (NJ): Prentice-Hall, Inc.; 1997.

[33] European Committee for Standardization. EN 206-1 Concrete - Part 1: Specification, performance, production and conformity. 2001.

[34] C.S.L.P. Nuove Norme Tecniche per le Costruzioni DM 14 gennaio 2008 - Gazzetta Ufficiale n. 29 del 4 febbraio 2008. 2009.

[35] European Committee for Standardization. UNI EN ISO 6892-1:2009 Metallic materials - Tensile testing Part 1: Method of test at room temperature. 2009

[36] European Committee for Standardization. ISO 527-2:2012. Plastics - Determination of tensile properties Part 2: Test conditions for moulding and extrusion plastics. 2012

[37] BASF Construction Chemicals Italia Spa. Technical sheet MasterBrace BAR 8 CFS. http://www.masterbuilders-solutions.basf.it/

[38] Dias SJE, Barros JAO. Performance of reinforced concrete T beams strengthened in shear with NSM CFRP laminates. Eng Struct 2010;32(2):373-84. http://dx.doi.org/10.1016/j.engstruct.2009.10.001

[39] Bianco V, Barros JAO, Monti G. New approach for modeling the contribution of NSM FRP strips for shear strengthening of RC beams. J Compos Constr 2010;14(1):36-48. http://dx.doi.org/10.1061/(ASCE)CC.1943-5614.0000048

[40] Mazaheripour H, Barros JAO, Sena-Cruz JM, Pepe M, Martinelli E. Experimental study on bond performance of GFRP bars in self-compacting steel fiber reinforced concrete. Compos Struct 2013;95:202-12. http://dx.doi.org/10.1016/j.compstruct.2012.07.009

[41] Dalfré GM, Barros JAO, Machado D. Steel bar - concrete bond behavior in the context of the ETS shear strengthening technique for RC beams. In: Proc: $53^{\circ}$ Brazilan Conference on Concret - IBRACON, Florianopolis, November 2011. p. 15.

[42] Bianco V, Monti G, Barros JA. Theoretical Model and Computational Procedure to Evaluate the NSM FRP Strips Shear Strength Contribution to a RC Beam. J Struct Eng 2011;137(11):1359-72. http://dx.doi.org/10.1061/(ASCE)ST.1943-541X.0000370 
[43] Rizzo A, De Lorenzis L. Behavior and capacity of RC beams strengthened in shear with NSM FRP reinforcement. Constr Build Mater 2009;23(4):1555-67.

http://dx.doi.org/10.1016/j.conbuildmat.2007.08.014

[44] Dias SJE, Barros JAO. Shear strengthening of RC T-section beams with low strength concrete using NSM CFRP laminates. Cem Concr Compos 2011;33(2):334-45.

http://dx.doi.org10.1016/j.cemconcomp.2010.10.002

[45] Pellegrino C, Modena C. Fiber Reinforced Polymer Shear Strengthening of Reinforced Concrete Beams with Transverse Steel Reinforcement. J Compos Constr 2002;6(2):104-11.

http://dx.doi.org10.1016/10.1061/(ASCE)1090-0268(2002)6:2(104)

[46] Bousselham A, Chaallal O. Effect of transverse steel and shear span on the performance of RC beams strengthened in shear with CFRP. Compos Part B Eng 2006;37:37(1)-46.

http://dx.doi.org/10.1016/j.compositesb.2005.05.012

[47] Grande E, Imbimbo M, Rasuolo A. Effect of transverse steel on the response of RC beams strengthened in shear by FRP: Experimental study. J Compos Constr 2009;13(5):405-14.

http://dx.doi.org/10.1061/(ASCE)1090-0268(2009)13:5(405)

[48] Dias SJE, Barros JAO. Experimental Behaviour of RC Beams Shear Strengthened with NSM CFRP Laminates. Strain 2011;48(1):88-100. http://dx.doi.org/10.1111/j.1475-1305.2010.00801.x 


\section{TABLES CAPTIONS}

Table 1 ETS shear strengthening configurations of the tested beams.

Table 2 Experimental results of 0S-Series, 2S-Series and 4S-Series.

Table 3 Significant strains measured for 0S- 2S- 4S-Series.

Table 4 Experimental results of previous experimental tests on beams strengthened with ETS technique. 
Table 1

ETS shear strengthening configurations of the tested beams.

\begin{tabular}{|c|c|c|c|c|c|c|c|c|c|}
\hline $\begin{array}{c}\text { Number } \\
\text { of bars }\end{array}$ & $\begin{array}{c}\text { Angle } \\
{\left[\theta_{\mathrm{fw}}\right]}\end{array}$ & $\begin{array}{c}\text { ETS bar } \\
\text { spacing } \\
{[\mathrm{Sfw}]}\end{array}$ & $\begin{array}{c}\text { ETS } \\
\text { Reinforcing } \\
\text { ratio }\left[\rho_{\mathrm{fw}}\right]\end{array}$ & \multicolumn{2}{|c|}{ OS-Ref ${ }^{c}$} & \multicolumn{2}{|c|}{$2 S-\operatorname{Ref}^{d}$} & \multicolumn{2}{|c|}{$4 S-\operatorname{Ref}^{e}$} \\
\hline $\mathrm{d}_{\mathrm{ETS}}$ & {$\left[{ }^{\circ}\right]^{\mathrm{a}}$} & $(\mathrm{mm})$ & {$[\%]^{\mathrm{b}}$} & $\left(\rho_{\mathrm{sw}}=0.0 \%\right)$ & $\begin{array}{c}\rho_{\mathrm{sw}}+\rho_{\mathrm{fw}} \\
{[\%]}\end{array}$ & $\left(\rho_{\mathrm{sw}}=0.10 \%\right)$ & $\begin{array}{c}\rho_{\mathrm{sw}}+\rho_{\mathrm{fw}} \\
{[\%]}\end{array}$ & $\left(\rho_{\mathrm{sw}}=0.17 \%\right)$ & $\begin{array}{c}\rho_{\mathrm{sw}}+\rho_{\mathrm{fw}} \\
{[\%]}\end{array}$ \\
\hline 3 & 90 & 300 & 0.15 & 0S-S300-90 & 0.15 & $2 \mathrm{~S}-\mathrm{S} 300-90$ & 0.25 & $4 S-S 300-90$ & 0.32 \\
\hline 3 & 45 & 300 & 0.21 & 0S-S300-45 & 0.21 & $2 \mathrm{~S}-\mathrm{S} 300-45$ & 0.31 & $4 S-S 300-45$ & 0.38 \\
\hline 5 & 90 & 180 & 0.24 & 0S-S180-90 & 0.24 & 2S-S180-90 & 0.35 & $4 S-S 180-90$ & 0.42 \\
\hline 5 & 45 & 180 & 0.34 & 0S-S180-45 & 0.34 & $2 S-S 180-45$ & 0.45 & $4 \mathrm{~S}-\mathrm{S} 180-45$ & 0.52 \\
\hline 5 & 90 & 180 & 0.16 & -- & -- & 2S-C180-90 & 0.26 & $4 \mathrm{~S}-\mathrm{C} 180-90$ & 0.33 \\
\hline 5 & 90 & 180 & 0.22 & -- & -- & $2 \mathrm{~S}-\mathrm{C} 180-45$ & 0.32 & $4 \mathrm{~S}-\mathrm{C} 180-45$ & 0.39 \\
\hline
\end{tabular}

a Angle between the ETS bar and the beam's axis.

b The ETS percentage was obtained from Eq. (2).

${ }^{\mathrm{c}}$ Series of beams without steel stirrups (0S-Series) (Figure 1).

${ }^{\mathrm{d}}$ Series of beams with two stirrups (2S-Series) (Figure 2a).

e Series of beams with four stirrups (4S-Series) (Figure 2b). 
Table 2

Experimental results of 0S-Series, 2S-Series and 4S-Series.

\begin{tabular}{cccccccc}
\hline & $\begin{array}{c}\mathrm{F}_{\max } \\
{[\mathrm{kN}]}\end{array}$ & $\begin{array}{c}\mathrm{u}_{\mathrm{Lmax}} \\
{[\mathrm{mm}]}\end{array}$ & $\begin{array}{c}\Delta \mathrm{F} / \mathrm{F}_{\text {Ref }} \\
{[\%]}\end{array}$ & $\begin{array}{c}\mathrm{V}_{\max } \\
{[\mathrm{kN}]}\end{array}$ & $\begin{array}{c}\mathrm{V}_{\mathrm{f}(\exp )} \\
{[\mathrm{kN}]}\end{array}$ & $\begin{array}{c}\mathrm{CDC}_{\text {tang. }} \\
{\left[{ }^{\circ}\right]}\end{array}$ & $\begin{array}{c}\mathrm{CDC}_{\text {avg. }} \\
{\left[{ }^{\circ}\right]}\end{array}$ \\
\hline 0S-Ref & 156.1 & 4.66 & -- & 93.6 & -- & 34 & 39 \\
0S-S300-90 & 217.8 & 4.37 & 39.5 & 130.7 & 37.0 & 48 & 42 \\
& & & & & & 58 & 47 \\
0S-S300-45 & 348.6 & & 123.4 & 209.2 & 115.5 & & \\
0S-S180-90 & 256.8 & 4.31 & 64.6 & 154.1 & 60.5 & 63 & 44 \\
0S-S180-45 & 368.8 & 6.56 & 136.3 & 221.3 & 127.7 & 35 & 43 \\
\hline 2S-Ref & 242.1 & 4.70 & -- & 145.2 & -- & 45 & 39 \\
2S-S300-90 & 315.7 & 5.32 & 30.4 & 189.4 & 44.2 & 58 & 42 \\
2S-S300-45 & 407.1 & 7.03 & 68.2 & 244.3 & 99.0 & 48 & 39 \\
2S-S180-90 & 406.8 & 8.27 & 68.1 & 244.1 & 98.8 & 73 & 47 \\
2S-S180-45 & 504.7 & 8.37 & 108.5 & 302.8 & 157.6 & 70 & 49 \\
\hline 4S-Ref & 353.8 & 7.35 & -- & 212.3 & -- & 48 & 40 \\
4S-S300-90 & 370.9 & 7.43 & 4.8 & 222.6 & 10.3 & 32 & 46 \\
4S-S300-45 & 552.4 & 12.03 & 56.1 & 331.5 & 119.2 & 61 & 54 \\
4S-S180-90 & 413.2 & 6.32 & 16.8 & 247.9 & 35.6 & 52 & 54 \\
4S-S180-45 & 566.4 & 11.01 & 60.1 & 339.8 & 127.6 & 53 & 40 \\
\hline 2S-C180-90 & 370.485 & 5.89 & 53.1 & 222.3 & 77.1 & 62 & 60 \\
2S-C180-45 & 534.69 & 9.53 & 120.9 & 320.8 & 175.6 & 48 & 46 \\
4S-C180-90 & 376.875 & 6.20 & 6.5 & 226.1 & 13.9 & 49 & 52 \\
4S-C180-45 & 616.86 & 12.03 & 74.4 & 370.1 & 157.8 & 42 & 40 \\
\hline
\end{tabular}


Table 3

Significant strains measured for 0S- 2S- 4S-Series.

\begin{tabular}{|c|c|c|c|c|}
\hline Beam ID & SG & Element & $\begin{array}{c}\varepsilon_{\text {Fmax }} \\
{[\%]}\end{array}$ & $\begin{array}{c}\varepsilon_{\max } \\
{[\%]} \\
\left(\mathrm{u}_{\mathrm{L}} / \mathrm{u}_{\mathrm{Lmax}}\right)\end{array}$ \\
\hline \multirow[t]{2}{*}{ 0S-S300-90 } & 1 & S1 & 0.06 & $0.08(0.72)$ \\
\hline & 6 & S2 & -- & $0.29(0.66)$ \\
\hline \multirow[t]{2}{*}{ 0S-S300-45 } & 3 & S2 & -- & $0.92(0.62)$ \\
\hline & 8 & S3 & -- & $0.87(0.99)$ \\
\hline \multirow[t]{2}{*}{ 0S-S180-90 } & 1 & S2 & 0.16 & 0.17 \\
\hline & 4 & S3 & 0.59 & $1.06(2.23)$ \\
\hline \multirow[t]{2}{*}{ 0S-S180-45 } & 3 & S3 & 0.46 & $0.48(1.03)$ \\
\hline & 7 & S4 & -- & $0.64(0.89)$ \\
\hline 2S-Ref & 1 & St1 & 0.17 & $0.21(1.49)$ \\
\hline 2S-S300-90 & 1 & St1 & 0.14 & $0.19(1.26)$ \\
\hline \multirow[t]{4}{*}{$2 \mathrm{~S}-\mathrm{S} 300-45$} & 3 & St1 & 0.30 & $0.95(1.07)$ \\
\hline & 5 & S1 & 0.16 & $0.73(1.14)$ \\
\hline & 6 & S2 & 0.59 & $0.84(0.63)$ \\
\hline & 8 & S2 & 0.30 & $0.92(1.06)$ \\
\hline 2S-S180-90 & 3 & St1 & -- & $1.00(0.83)$ \\
\hline \multirow[t]{3}{*}{ 2S-S180-45 } & 2 & St1 & 0.42 & $0.56(1.13)$ \\
\hline & 5 & S2 & 0.30 & 0.31 \\
\hline & 8 & S3 & 0.29 & $0.31(1.11)$ \\
\hline \multirow[t]{2}{*}{ 4S-Ref } & 1 & St1 & 0.47 & $0.47(1.00)$ \\
\hline & 2 & St2 & 0.75 & $0.86(0.50)$ \\
\hline 4S-S300-90 & 6 & S2 & 0.16 & $0.16(1.00)$ \\
\hline \multirow[t]{5}{*}{ 4S-S300-45 } & 1 & St1 & 0.25 & $0.31(1.10)$ \\
\hline & 3 & St2 & -- & $0.89(0.69)$ \\
\hline & 4 & S1 & -- & $0.38(0.82)$ \\
\hline & 6 & S2 & -- & $0.91(0.75)$ \\
\hline & 8 & S2 & -- & $0.90(0.82)$ \\
\hline \multirow[t]{3}{*}{ 4S-S180-90 } & 2 & St2 & 0.26 & $0.38(1.06)$ \\
\hline & 4 & S2 & 0.04 & $0.05(1.05)$ \\
\hline & 7 & S3 & 0.88 & $1.00(1.02)$ \\
\hline \multirow[t]{4}{*}{ 4S-S180-45 } & 1 & St1 & 0.41 & 0.48 \\
\hline & 3 & St2 & -- & $0.96(0.92)$ \\
\hline & 5 & S2 & 0.66 & $0.82(1.20)$ \\
\hline & 8 & $\mathrm{~S} 3$ & 0.26 & $0.27(1.20)$ \\
\hline \multirow[t]{4}{*}{ 2S-C180-90 } & 2 & St1 & -- & $0.87(0.79)$ \\
\hline & $1^{*}$ & $\mathrm{C} 2$ & 0.40 & $0.46(1.31)$ \\
\hline & 4 & $\mathrm{C} 3$ & 0.27 & $0.38(0.82)$ \\
\hline & 8 & $\mathrm{C} 4$ & 0.67 & $0.67(1.00)$ \\
\hline \multirow[t]{6}{*}{ 2S-C180-45 } & 2 & $\mathrm{C} 2$ & 0.66 & $0.76(1.20)$ \\
\hline & $1 *$ & $\mathrm{C} 2$ & 0.46 & $0.56(0.70)$ \\
\hline & 4 & C3 & 0.24 & $0.61(0.63)$ \\
\hline & 6 & $\mathrm{C} 4$ & -- & $0.97(0.92)$ \\
\hline & 7 & $\mathrm{C} 4$ & -- & $1.00(0.83)$ \\
\hline & 8 & $\mathrm{C} 4$ & 0.86 & $0.86(1.00)$ \\
\hline \multirow[t]{2}{*}{ 4S-C180-90 } & 4 & $\mathrm{C} 2$ & 0.15 & $0.16(1.05)$ \\
\hline & 6 & C3 & 0.13 & $0.15(0.60)$ \\
\hline \multirow[t]{4}{*}{ 4S-C180-45 } & 3 & St2 & -- & $0.79(0.78)$ \\
\hline & 5 & $\mathrm{C} 2$ & 0.77 & $0.86(1.18)$ \\
\hline & 8 & C3 & 0.62 & 0.89 (1.18) \\
\hline & 2 & $\mathrm{C} 4$ & 0.86 & $0.86(1.00)$ \\
\hline
\end{tabular}


Table 4

Experimental results of previous experimental tests on beams strengthened with ETS technique.

\begin{tabular}{ccccccccc}
\hline Valerio et al 2009 [11] & $\begin{array}{c}\text { Angle } \\
{\left[\theta_{\mathrm{fw}}\right]}\end{array}$ & Material & $\begin{array}{c}\mathrm{f}_{\mathrm{cm}, \mathrm{cube}} / \mathrm{f}_{\mathrm{cm}} \\
{[\mathrm{MPa}]}\end{array}$ & $\begin{array}{c}\rho_{\mathrm{sw}} \\
{[\%]}\end{array}$ & $\begin{array}{c}\rho_{\mathrm{fw}} \\
{[\%]}\end{array}$ & $\begin{array}{c}\rho_{\mathrm{sw}}+\rho_{\mathrm{fw}} \\
{[\%]}\end{array}$ & $\begin{array}{c}\Delta \mathrm{F} / \mathrm{F}_{\mathrm{Ref}} \\
{[\%]}\end{array}$ & $\begin{array}{c}\mathrm{V}_{\mathrm{f}} \\
{[\mathrm{kN}]}\end{array}$ \\
\hline SLB P4d-2S8@d & $90^{\circ}$ & $\mathrm{S}$ & {$[55-60]^{\mathrm{a}}$} & 0.00 & 0.09 & 0.09 & 18.0 & 53.2 \\
SSB R3d-C6@0·7d & $90^{\circ}$ & $\mathrm{C}$ & {$[55-60]^{\mathrm{a}}$} & 0.00 & 0.24 & 0.24 & 97.0 & 22.9 \\
SSB R3d-C6@0.5d & $90^{\circ}$ & $\mathrm{C}$ & {$[55-60]^{\mathrm{a}}$} & 0.00 & 0.34 & 0.34 & 114.0 & 27.0 \\
SLB P4d-2C7.5@d & $90^{\circ}$ & $\mathrm{C}$ & {$[55-60]^{\mathrm{a}}$} & 0.00 & 0.08 & 0.08 & 14.6 & 43.2 \\
SLB P4d-C7-5@d & $90^{\circ}$ & $\mathrm{C}$ & {$[55-60]^{\mathrm{a}}$} & 0.00 & 0.04 & 0.04 & 6.5 & 19.1 \\
Chaallal et al 2011 [14] & & & & & & & & \\
\hline S0-ETS & $90^{\circ}$ & $\mathrm{C}$ & $25.00^{\mathrm{b}}$ & 0.00 & 0.64 & 0.64 & 112.40 & 99.50 \\
Dalfré and Barros 2013 [15] & & & & & & & & \\
\hline A.3 E300.90 & $90^{\circ}$ & $\mathrm{S}$ & $30.78^{\mathrm{b}}$ & 0.00 & 0.17 & 0.17 & 47.7 & 31.2 \\
A.4 E300.45 & $45^{\circ}$ & $\mathrm{S}$ & $28.81^{\mathrm{b}}$ & 0.00 & 0.25 & 0.25 & 47.7 & 57.1 \\
A.5 S300.90/E300.90 & $90^{\circ}$ & $\mathrm{S}$ & $30.78^{\mathrm{b}}$ & 0.13 & 0.17 & 0.30 & 40.8 & 40.3 \\
B.3 E300.90 & $90^{\circ}$ & $\mathrm{S}$ & $30.78^{\mathrm{b}}$ & 0.00 & 0.11 & 0.11 & 17.5 & 21.3 \\
B.4 E300.45 & $45^{\circ}$ & $\mathrm{S}$ & $28.81^{\mathrm{b}}$ & 0.00 & 0.16 & 0.16 & 65.3 & 98.5 \\
B.5 S300.90/E300.90 & $90^{\circ}$ & $\mathrm{S}$ & $30.78^{\mathrm{b}}$ & 0.06 & 0.11 & 0.17 & 67.9 & 94.7 \\
\hline
\end{tabular}

${ }^{\mathrm{a}} \mathrm{f}_{\mathrm{cm} \text {, cube. }}$ Average concrete cube compressive strength

${ }^{\mathrm{b}} \mathrm{f}_{\mathrm{cm} . .}$ Average concrete cylindrical compressive strength 


\section{FIGURE CAPTIONS}

Fig. 1. Tested beams: geometry, steel reinforcements applied in all beams (dimensions in mm).

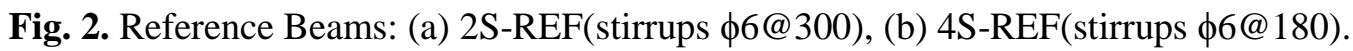

Fig. 3. Strengthening configurations of series: (a) $0 \mathrm{~S}$, (b) $2 \mathrm{~S}$; (c) $4 \mathrm{~S}$ (dimensions in $\mathrm{mm}$ ).

Fig. 4. Test set-up.

Fig. 5. Position of the strain gauges (dimensions in $\mathrm{mm}$ )

Fig. 6. Force vs deflection at the loaded section for (a) 0S-Series, (b) $2 \mathrm{~S}$-Series, (c) 4S-Series.

Fig. 7. Crack Patterns at Maximum Load.

Fig. 8. Load versus strains recorded in strain gauges applied in ETS bars and steel stirrups.

Fig. 9. Failure (a-b) loss of bond in ETS steel bars and CFRP roads, respectively, (c) scratching of the epoxy adhesive (d) peeling-off of the CFRP road.

Fig. 10. Influence of the $\rho_{\mathrm{sw}}+\rho_{\mathrm{fw}}$ on the ETS effectiveness.

Fig. 11. ETS effectiveness (a) influence of $\rho_{\mathrm{sw}}$ and $\rho_{\mathrm{fw}}$, (b) projection on the plane $\Delta \mathrm{F} / \mathrm{F}_{\mathrm{Ref}}-\rho_{\mathrm{fw}}$.

Fig. 12. Comparison of shear strengthening efficiency between ETS, NSM and EBR techniques [48]. 


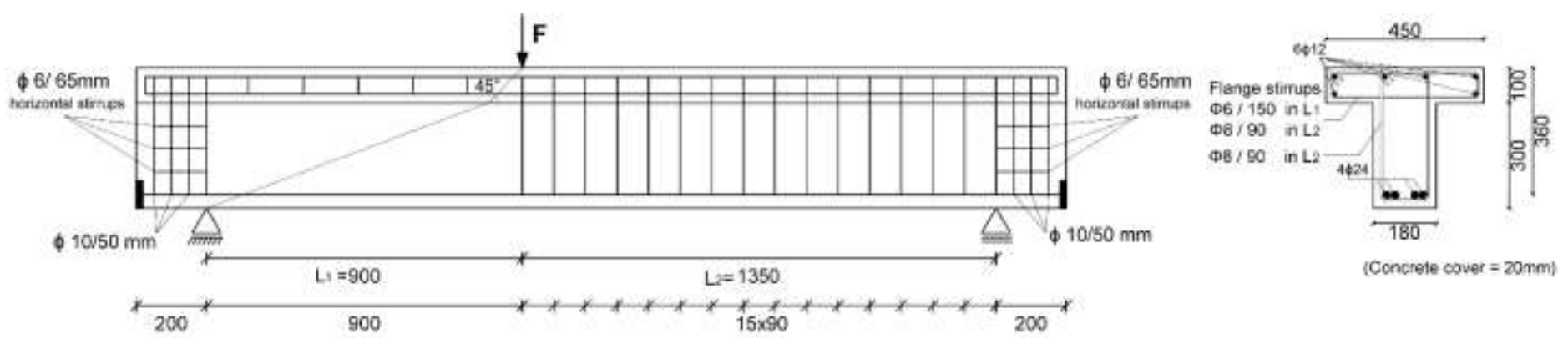

Fig. 1. Tested beams: geometry, steel reinforcements applied in all beams (dimensions in $\mathrm{mm}$ ). 


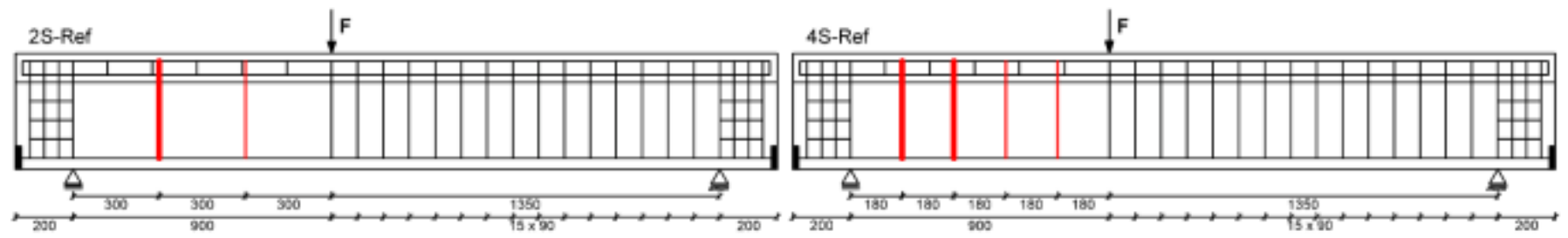

(a)

(b)

Fig. 2. Reference Beams: (a) 2S-REF(stirrups $\phi 6 @ 300)$, (b) 4S-REF(stirrups $\phi 6 @ 180$ ) 

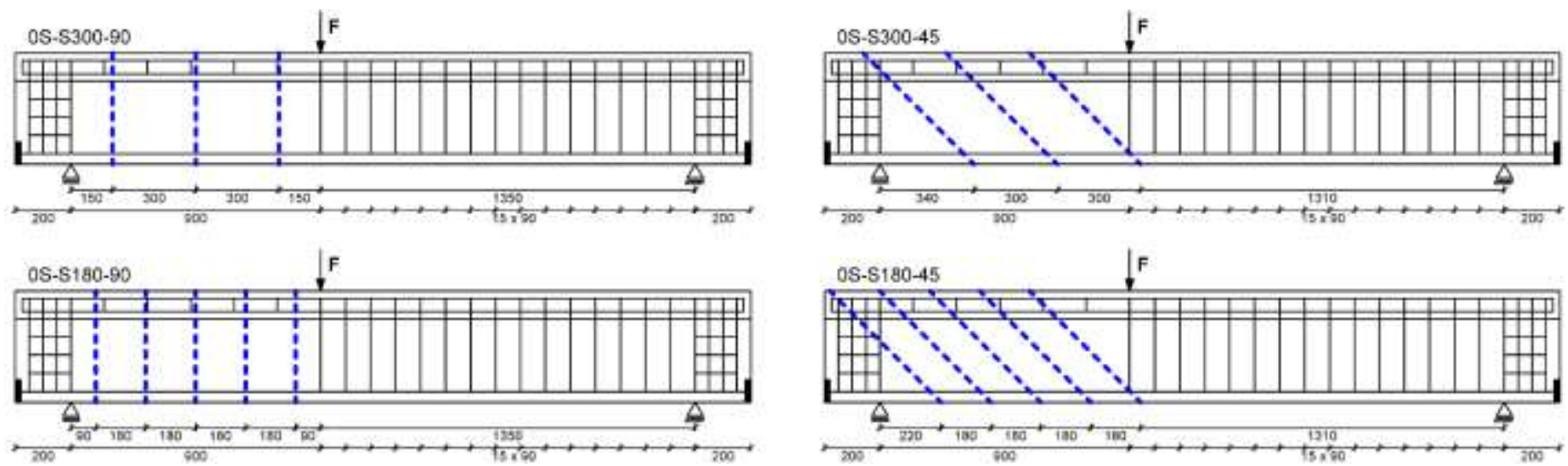

(a)
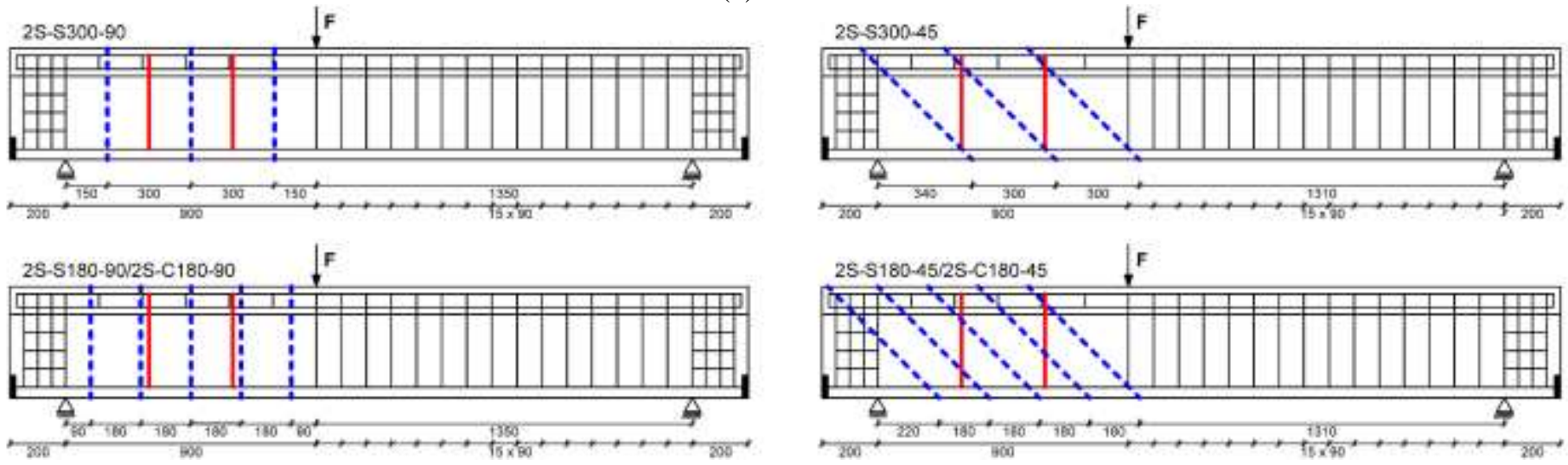

(b)
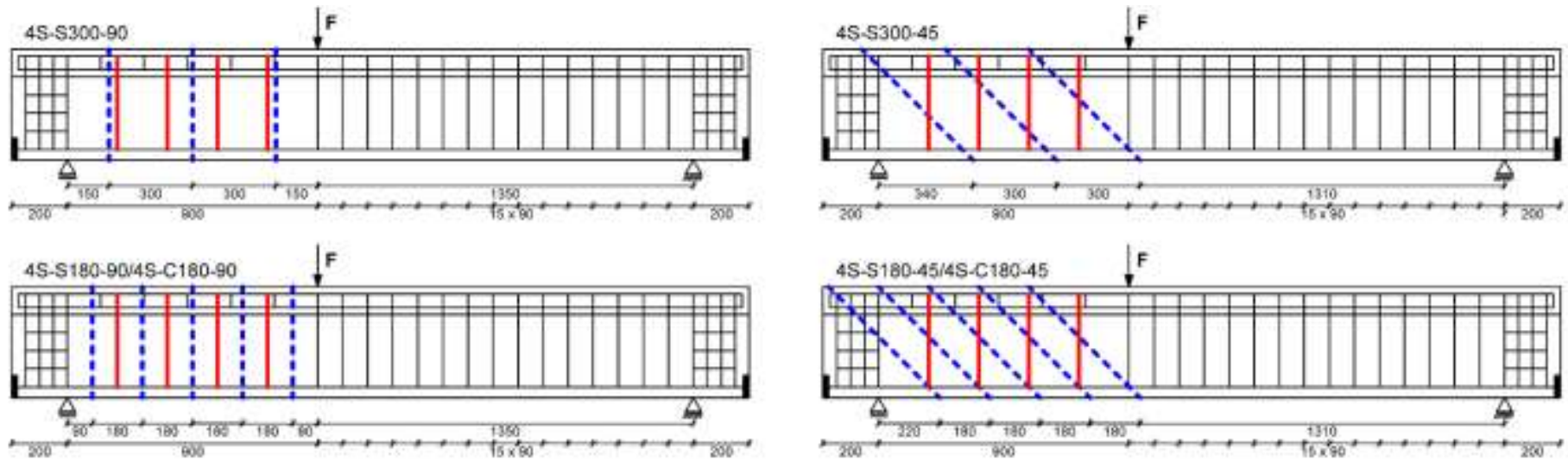

(c)

Fig. 3. Strengthening configurations of series: (a) $0 \mathrm{~S}$, (b) $2 \mathrm{~S}$; (c) $4 \mathrm{~S}$ (dimensions in $\mathrm{mm}$ ). 


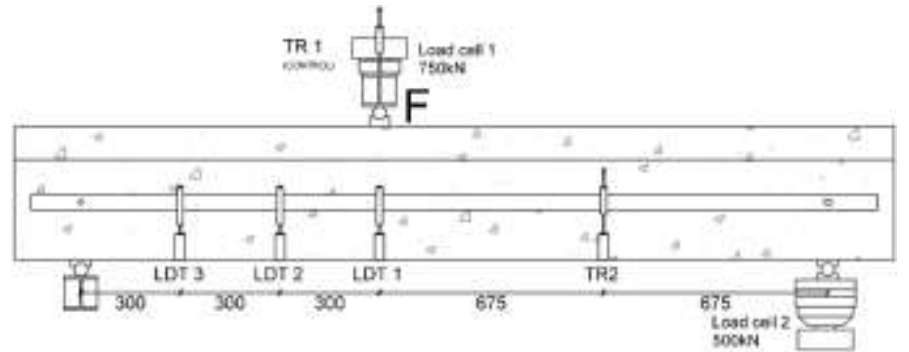

Fig. 4. Test set-up. 

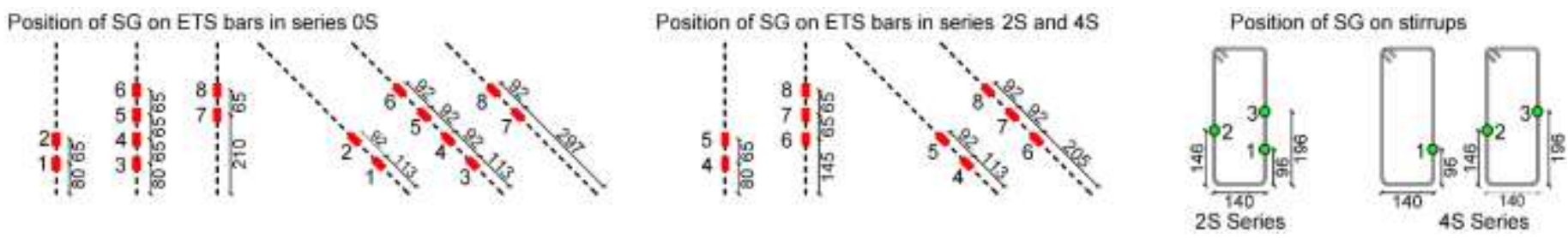

(a)
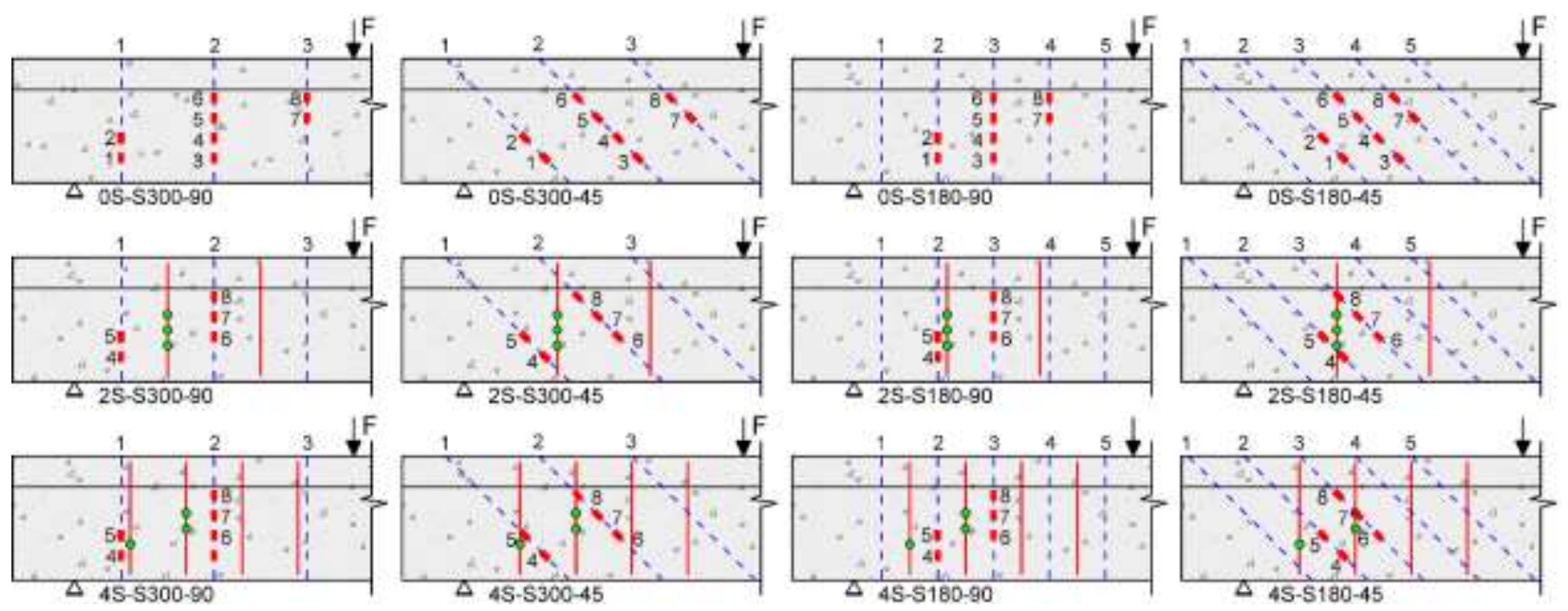

b)
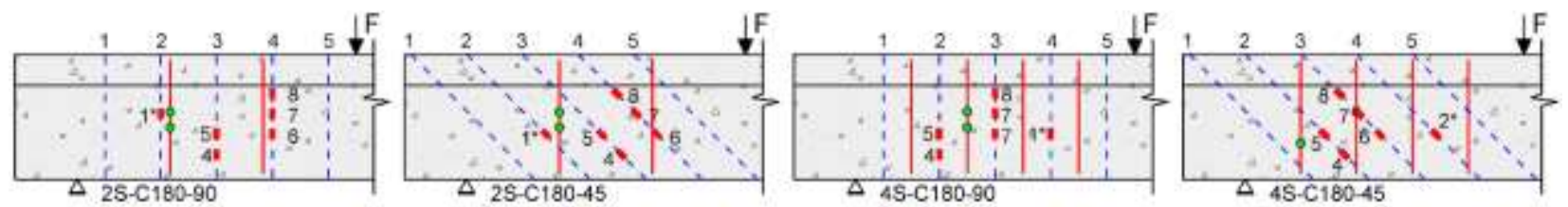

(c)

Fig. 5. Position of the strain gauges (dimensions in $\mathrm{mm}$ ). 


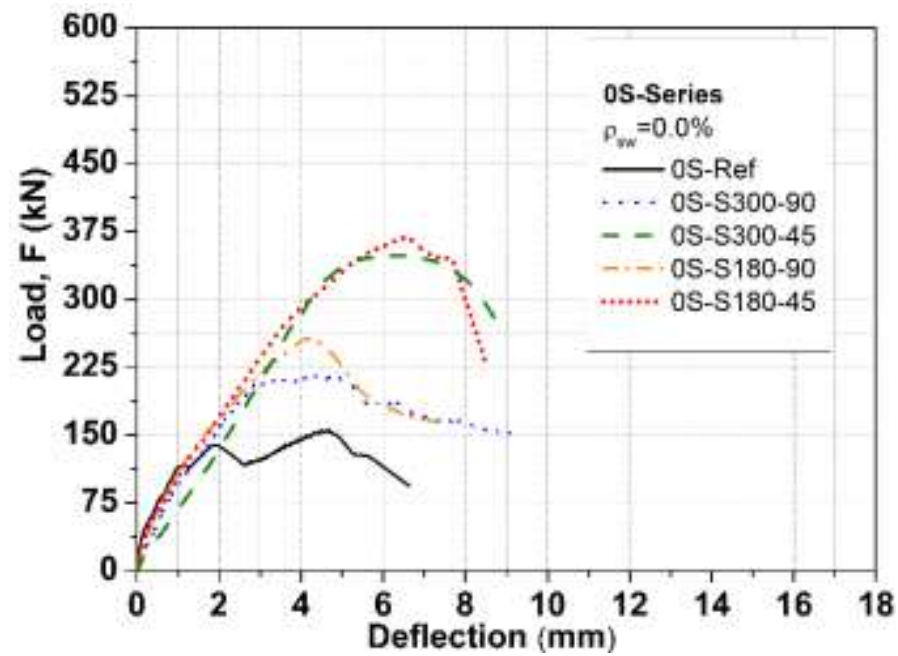

(a)

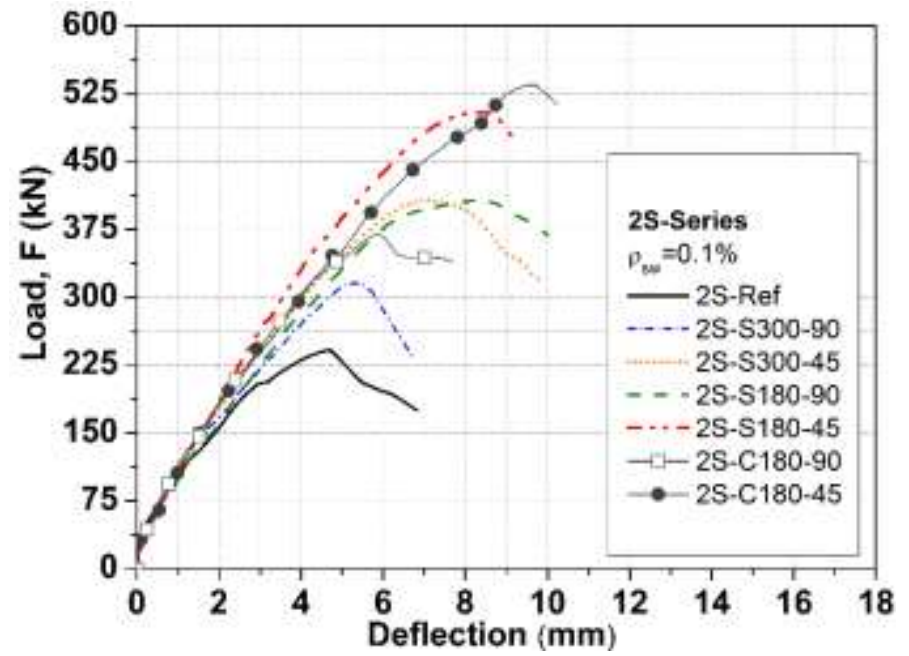

(b)

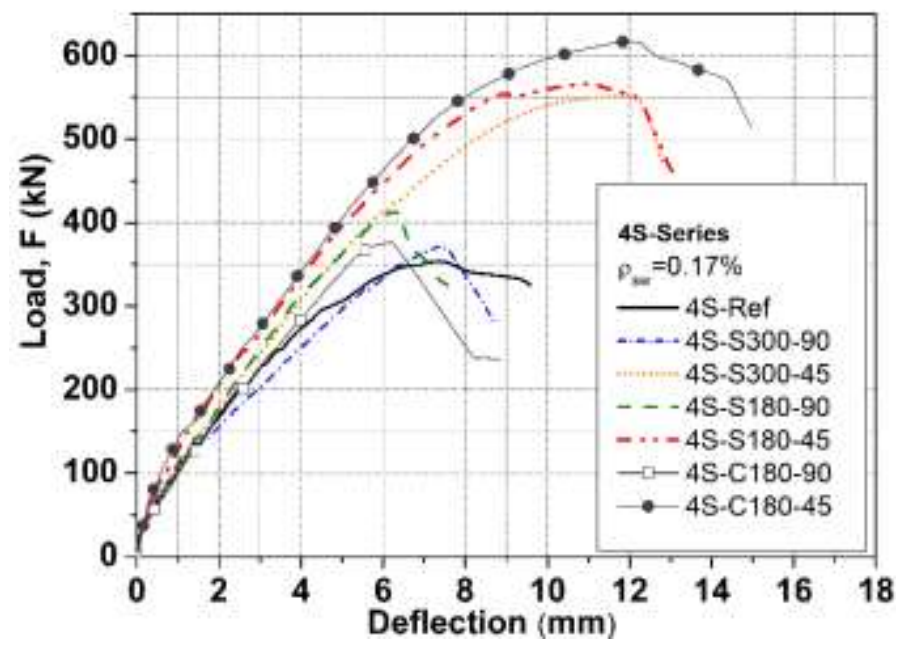

(c)

Fig. 6. Force vs deflection at the loaded seciton for (a) $0 \mathrm{~S}$-Series, (b) $2 \mathrm{~S}$-Series, (c) $4 \mathrm{~S}$-Series. 

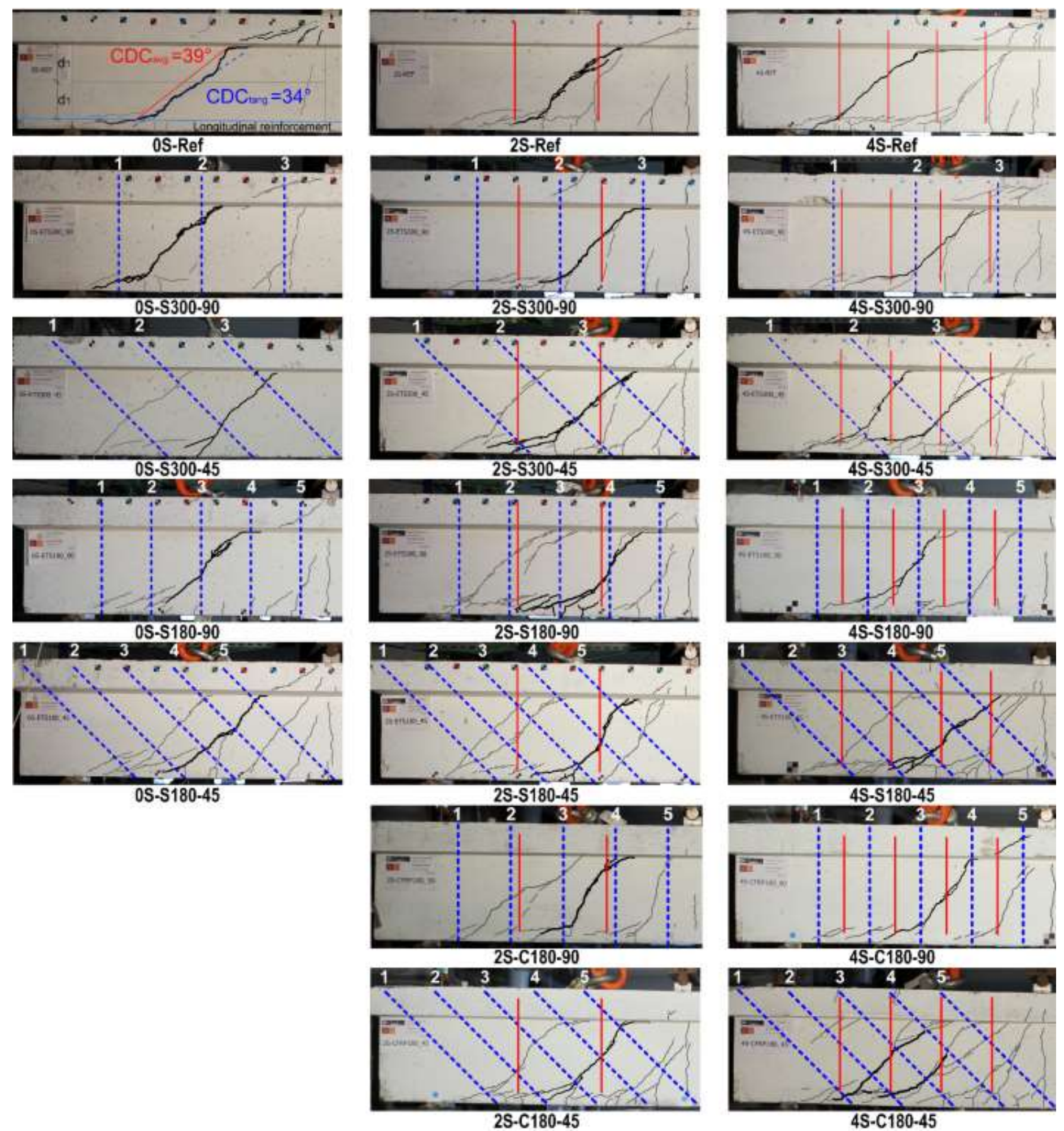

Fig. 7. Crack Patterns at Maximum Load. 


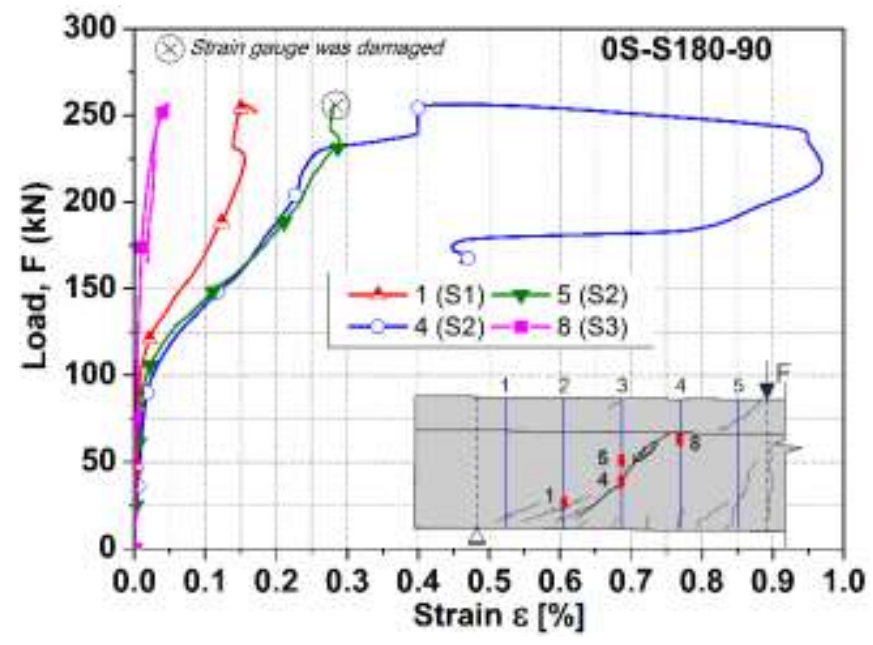

(a)

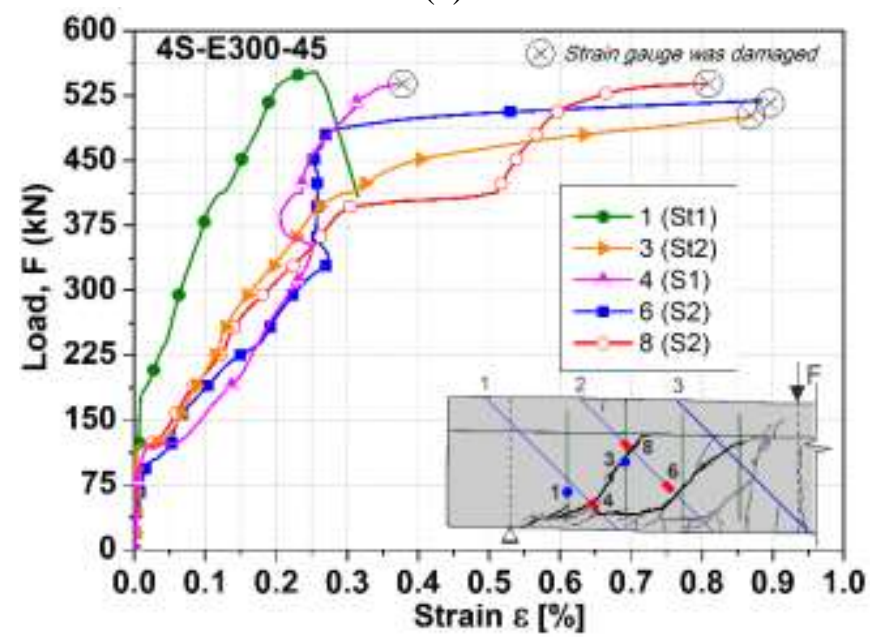

(c)

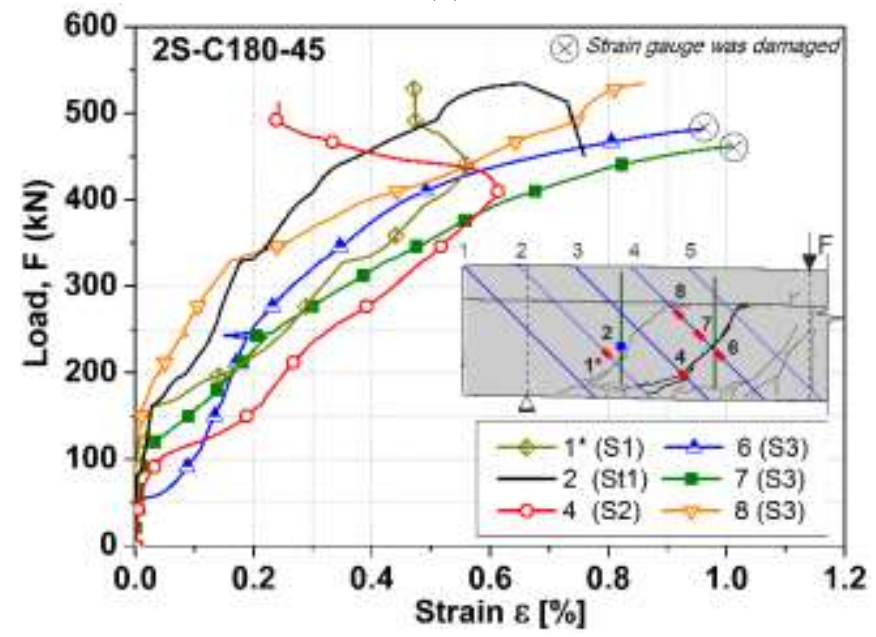

(e)

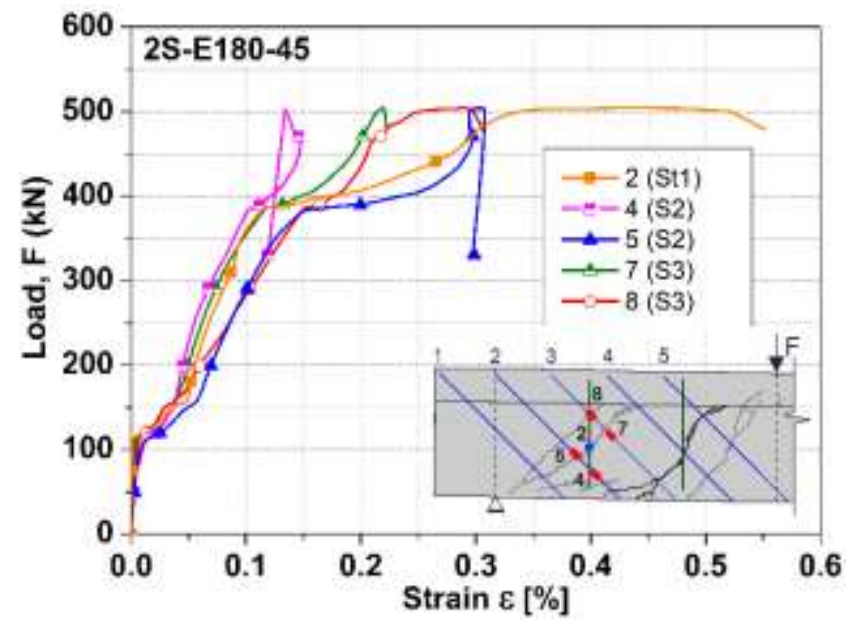

(b)

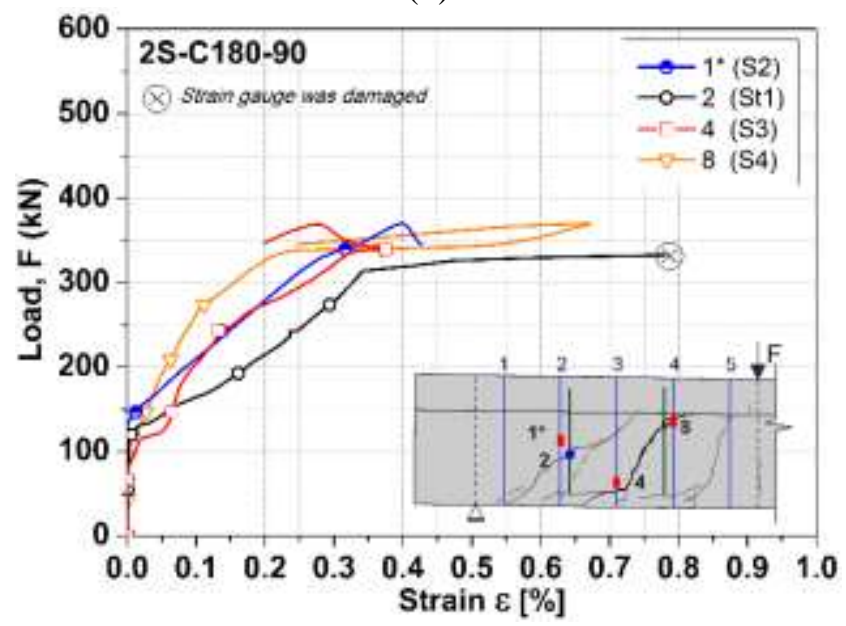

(d)

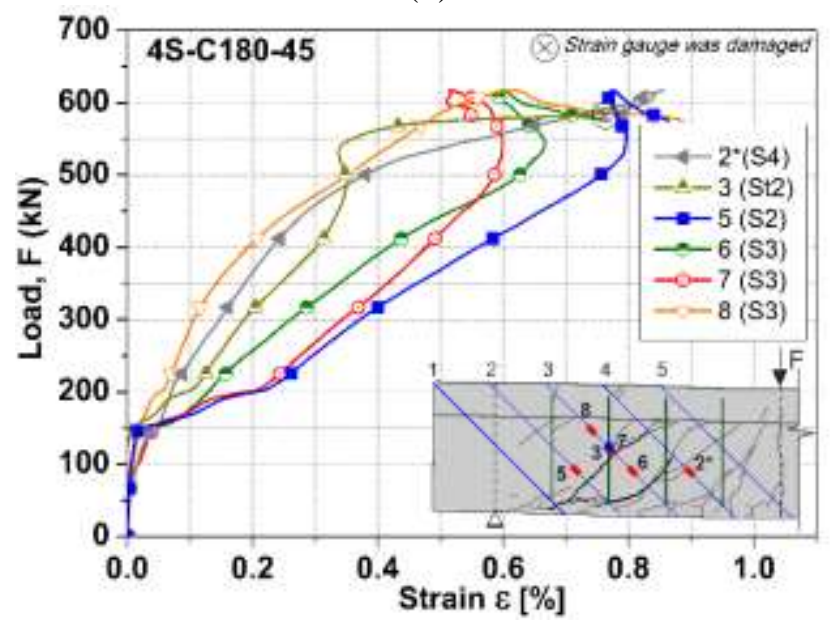

(f)

Fig. 8. Load versus strains recorded in strain gauges applied in ETS bars and steel stirrups. 

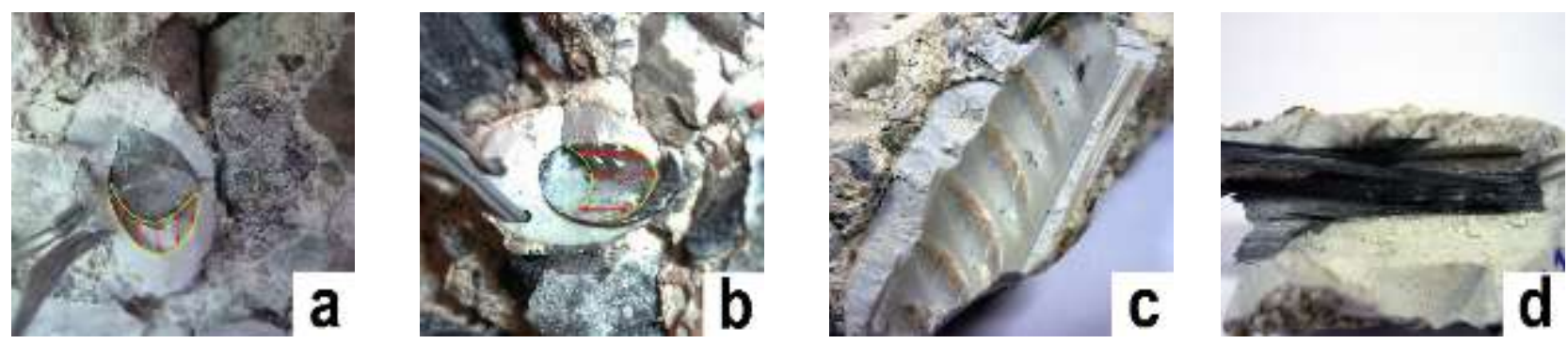

Fig.9. Failure (a-b) loss of bond in ETS steel bars and CFRP roads, respectively, (c) scratching of the epoxy adhesive (d) peeling-off of the CFRP road. 


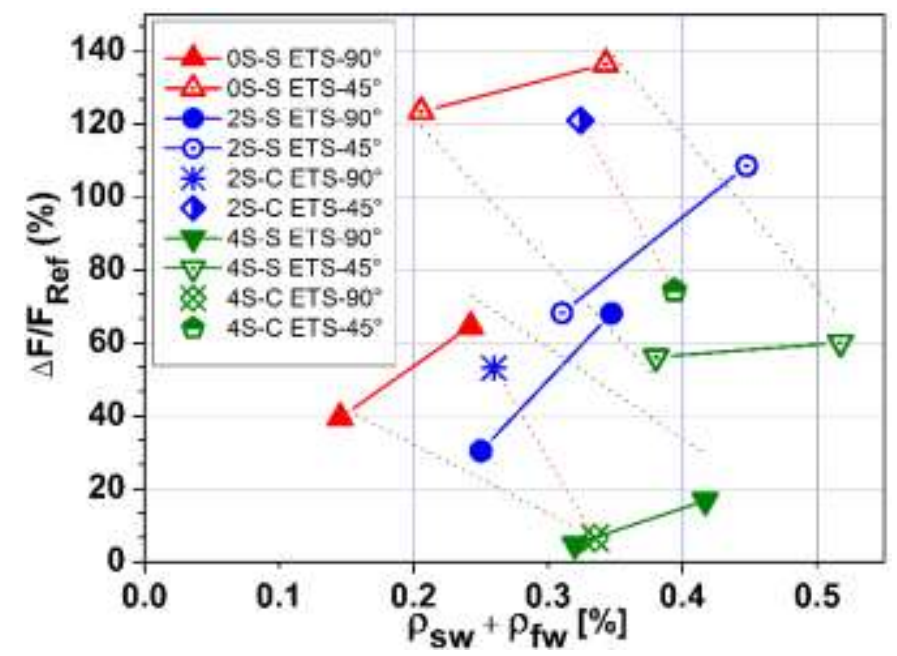

Fig. 10. Influence of the $\rho_{\mathrm{sw}}+\rho_{\mathrm{fw}}$ on the ETS effectiveness. 


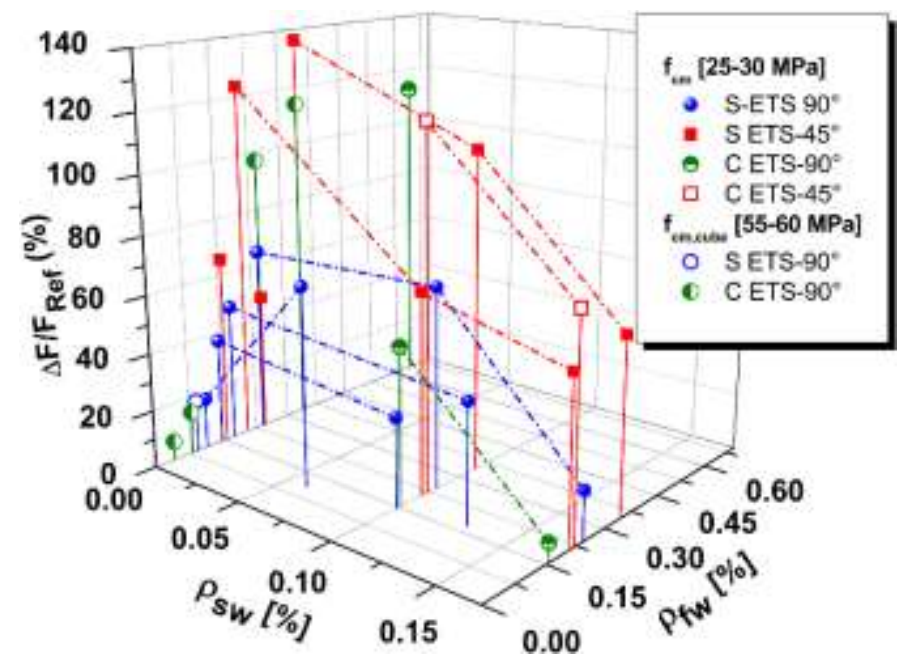

(a)

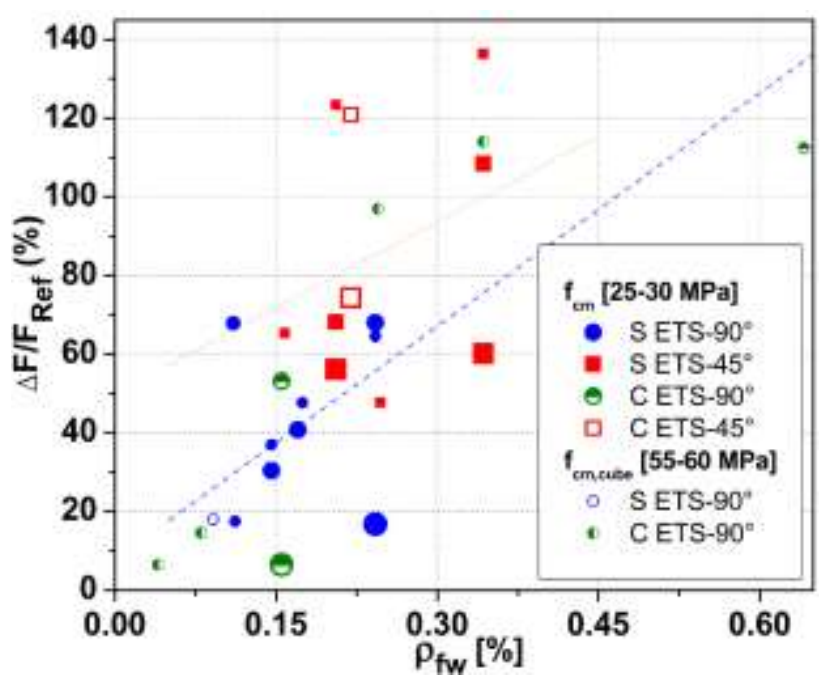

(b)

Fig. 11. ETS effectiveness (a) influence of $\rho_{\mathrm{sw}}$ and $\rho_{\mathrm{fw}}$, (b) projection on the plane $\Delta F / F_{\text {Ref }}-\rho_{\mathrm{fw}}$. 


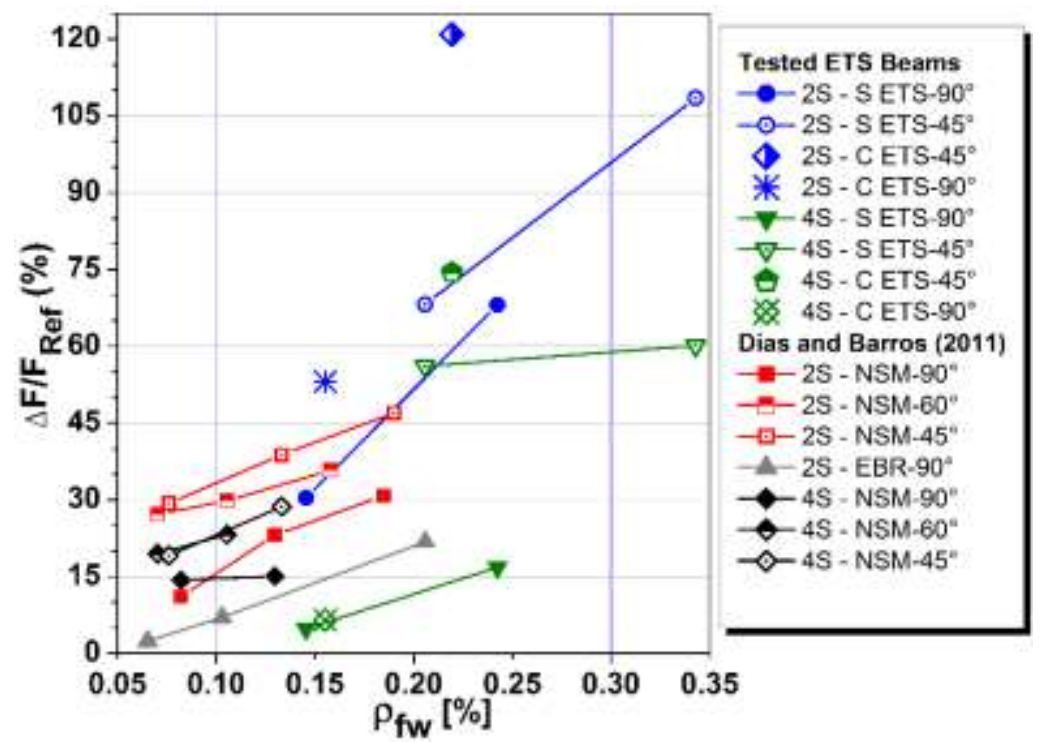

Fig. 12. Comparison of shear strengthening efficiency between ETS, NSM and EBR techniques [48]. 